\title{
Semiconductor-type $\mathrm{SnO}_{2}$-based $\mathrm{NO}_{2}$ sensors operated at room temperature under UV-light irradiation
}

Takeo Hyodo*, Kaoru Urata, Kai Kamada, Taro Ueda, and Yasuhiro Shimizu

Graduate School of Engineering, Nagasaki University

1-14 Bunkyo-machi, Nagasaki 852-8521, Japan

*Corresponding author:

Takeo Hyodo, Dr.

Graduate School of Science and Technology, Nagasaki University

1-14 Bunkyo-machi, Nagasaki 852-8521, Japan

Tel: +81-95-819-2644

Fax: +81-95-819-2643

E-mail: hyodo@nagasaki-u.ac.jp 


\begin{abstract}
$\mathrm{NO}_{2}$-sensing properties of typical oxide $\left(\mathrm{SnO}_{2}, \mathrm{In}_{2} \mathrm{O}_{3}\right.$, or $\left.\mathrm{WO}_{3}\right)$-based semiconductor gas sensors were measured at $30^{\circ} \mathrm{C}$ with and without UV-light irradiation (main wavelength: 365 $\mathrm{nm})$, and effects of noble-metal (Pd or Pt) loading, UV-light intensity $\left(0-134 \mathrm{~mW} \mathrm{~cm}^{-2}\right)$ and relative humidity in target gas $(0-80 \% \mathrm{RH})$ on their $\mathrm{NO}_{2}$-sensing properties were investigated in this study. The UV-light irradiation effectively reduced the resistances of all sensors, enhanced their $\mathrm{NO}_{2}$ responses in some cases, and tended to accelerate their response and recovery speeds in dry air, because the UV-light irradiation promoted the adsorption and desorption of $\mathrm{NO}_{2}$-species on the surface. The $\mathrm{SnO}_{2}$ sensor showed the largest $\mathrm{NO}_{2}$ response in dry air, among all the pristine oxide sensors, especially under weak UV-light irradiation $(\leq 35$ $\mathrm{mW} \mathrm{cm}{ }^{-2}$ ), together with relatively fast response and recovery speeds. The Pd or Pt loading onto $\mathrm{SnO}_{2}$ enhanced the $\mathrm{NO}_{2}$ response of the $\mathrm{SnO}_{2}$ sensor and accelerated their response and recovery speeds in dry air, while XPS analysis indicated that most of the Pd and Pt nanoparticles loaded on the surface were oxidized after heat treatment at $500^{\circ} \mathrm{C}$. Among all the sensors, the $0.05 \mathrm{wt} \%$ Pd-loaded $\mathrm{SnO}_{2}$ sensor showed the largest $\mathrm{NO}_{2}$ response under weak UV-light irradiation $\left(\leq 35 \mathrm{~mW} \mathrm{~cm}^{-2}\right)$, together with relatively fast response and recovery speeds. The addition of moisture to the target gas had adverse effects on the $\mathrm{NO}_{2}$ responses and the response speeds of the $\mathrm{SnO}_{2}$ and $0.05 \mathrm{wt} \%$ Pd-loaded $\mathrm{SnO}_{2}$ sensors, but the weak UV-light irradiation (7 $\mathrm{mW} \mathrm{cm}{ }^{-2}$ ) largely reduced the dependence of the $\mathrm{NO}_{2}$ response of the $0.05 \mathrm{Pd} / \mathrm{SnO}_{2}$ sensor on relative humidity while maintaining the large $\mathrm{NO}_{2}$ response, probably because the weak UVlight irradiation promotes the desorption of physisorbed water molecules and then the effective adsorption of $\mathrm{NO}_{2}$ on the $0.05 \mathrm{Pd} / \mathrm{SnO}_{2}$ surface.
\end{abstract}

Keywords: $\mathrm{NO}_{2}$ sensor; UV-light irradiation; tin dioxide; noble metal; room temperature 


\section{Introduction}

Nitrogen dioxides $\left(\mathrm{NO}_{2}\right)$, one of gaseous air pollutants in modern society, are emitted in large amounts from various fossil-fuel combustion systems operated at elevated temperatures. Not only does $\mathrm{NO}_{2}$ cause negative impacts on human health (e.g., an increase in respiratory symptoms and a reduction in pulmonic function) directly $[1,2]$, but also it reacts with waterbased chemicals in the atmosphere to form acid rain causing severe environmental destruction [3]. In addition, $\mathrm{NO}_{2}$ reacts also with various chemicals (e.g., volatile organic compounds) in the atmosphere under sunlight irradiation, to form other air pollutants such as suspended particulate matters and photochemical oxidants such as ozone, aldehydes, and peroxyacetyl nitrates, and these products also gave a serious risk to human health $[4,5]$. Therefore, numerous efforts have been so far directed to developing various types of $\mathrm{NO}_{2}$-sensing devices such as solid electrochemical [6-8], optical [9, 10], and acoustic sensors [11, 12]. Among them, it is well known that semiconductor gas sensors show relatively large sensitivity and excellent selectivity to $\mathrm{NO}_{2}$ at elevated temperatures, and $\mathrm{SnO}_{2}$ [13-16], $\mathrm{In}_{2} \mathrm{O}_{3}$ [17-19], $\mathrm{WO}_{3}$ [20-23], and the related materials are especially promising candidates as the $\mathrm{NO}_{2}$-sensing materials, among all the oxide semiconductors. However, the operation of these semiconductor gas sensors at elevated temperatures causes sintering among oxide particles and the grain growth involved, leading to reduction in the $\mathrm{NO}_{2}$ sensitivity. The $\mathrm{UV}$ and/or visible-light irradiation to the semiconductor gas sensors is one of attractive approaches to solving such problems, because it can reduce the sensor resistance to allow the semiconductor gas sensors to operate even at room temperature (RT). Therefore, $\mathrm{NO}_{2}$-sensing properties of the semiconductor gas sensors (e.g., $\mathrm{SnO}_{2}$ [24-26], $\mathrm{In}_{2} \mathrm{O}_{3}[27,28], \mathrm{WO}_{3}$ [29]) under $\mathrm{UV}$ and/or visible-light irradiation have been recently reported by many researchers, to improve the disadvantages of the operation at elevated temperatures. We also have already demonstrated that UV-light irradiation (main wavelength: $365 \mathrm{~nm}$ ) enhanced $\mathrm{NO}_{2}$-sensing properties of $\mathrm{SnO}_{2}$-based sensors at $\mathrm{RT}$ and the 
Pd loading onto $\mathrm{SnO}_{2}$ which was prepared by a hydrothermal method improved their $\mathrm{NO}_{2}-$ sensing properties at RT under UV-light irradiation [30-32]. In this study, differences in $\mathrm{NO}_{2}-$ sensing properties between $\mathrm{SnO}_{2}, \mathrm{In}_{2} \mathrm{O}_{3}$, and $\mathrm{WO}_{3}$ sensors with and without UV-light irradiation and effects of the UV-light intensity on their $\mathrm{NO}_{2}$-sensing properties were first examined at $30^{\circ} \mathrm{C}$ in air. In addition, impacts of the amount of $\mathrm{Pd}$ or Pt loading mainly onto the $\mathrm{SnO}_{2}$ surface and the amount of moisture (i.e., humidity) in target gas on their $\mathrm{NO}_{2}$-sensing properties were systematically investigated at $30^{\circ} \mathrm{C}$ in air.

\section{Experimental}

\subsection{Preparation of $\mathrm{SnO}_{2}, \mathrm{In}_{2} \mathrm{O}_{3}$, and $\mathrm{WO}_{3}$ powders and loading of Pd or Pt onto their oxide}

\section{surface}

$\mathrm{SnO}_{2}$ powder was prepared according to the following procedure. An appropriate amount of $\mathrm{NH}_{4} \mathrm{HCO}_{3}$ aqueous solution $\left(1.0 \mathrm{~mol} \mathrm{dm}^{-3}\right)$ was added into $\mathrm{SnCl}_{4}$ aqueous solution $(1.0 \mathrm{~mol}$ $\mathrm{dm}^{-3}$ ). The obtained white precipitate was repeatedly centrifuged at a speed of $4500 \mathrm{rpm}$ for 20 min and washed with pure water, and then dried at $100^{\circ} \mathrm{C}$ for $18 \mathrm{~h}$ in ambient air. The resultant powder was calcined at $600^{\circ} \mathrm{C}$ for $1 \mathrm{~h}$ in ambient air, to obtain $\mathrm{SnO}_{2}$ powder. It was confirmed that the crystal structure of the prepared powder was tetragonal $\mathrm{SnO}_{2}$ (JCPDS No. 41-1445) by X-ray diffraction (XRD) analysis (Rigaku Corp., RINT2200) using Cu Ka radiation (40 kV, 36 $\mathrm{mA}$ ). $\mathrm{In}_{2} \mathrm{O}_{3}$ powder, of which crystal structure was assigned to cubic (JCPDS No. 6-416) by XRD analysis, was prepared by pyrolyzing $\mathrm{In}\left(\mathrm{NO}_{3}\right)_{3}$, which was dissolved in pure water, and followed by calcination at $600^{\circ} \mathrm{C}$ for $1 \mathrm{~h}$ in ambient air. $\mathrm{WO}_{3}$ powder was prepared according to the following procedure. An appropriate amount of $\mathrm{HNO}_{3}$ aqueous solution $\left(0.8 \mathrm{~mol} \mathrm{dm} \mathrm{dm}^{-3}\right)$ was added into $\mathrm{NaWO}_{4}$ aqueous solution $\left(0.15 \mathrm{~mol} \mathrm{dm}^{-3}\right)$. The yellow resultant precipitate was repeatedly centrifuged at a speed of $4500 \mathrm{rpm}$ for $20 \mathrm{~min}$ and washed with pure water, and then dried at $100^{\circ} \mathrm{C}$ for $18 \mathrm{~h}$ in ambient air. The resultant powder was calcined at $500^{\circ} \mathrm{C}$ for $2 \mathrm{~h}$ in 
ambient air, to obtain $\mathrm{WO}_{3}$ powder. It was confirmed that the crystal structure of the prepared powder was monoclinic $\mathrm{WO}_{3}$ (JCPDS No. 43-1035) by XRD analysis. Specific surface area of the $\mathrm{SnO}_{2}, \mathrm{In}_{2} \mathrm{O}_{3}$, or $\mathrm{WO}_{3}$ powder obtained, which was measured by the Brunauer-EmmettTeller (BET) method using $\mathrm{N}_{2}$ adsorption-desorption isotherms (Micromeritics Instrument Corp., Tristar3000), was 21.2, 23.7, or $12.0 \mathrm{~m}^{2} \mathrm{~g}^{-1}$, respectively.

In some cases, Pd or Pt nanoparticles were loaded onto the surface of these oxide powders. After an appropriate amount of oxide powders was added into $\mathrm{Pd}\left(\mathrm{NO}_{3}\right)_{2}$ or $\mathrm{PtCl}_{4}$ aqueous solution $\left(0.75 \mathrm{~mol} \mathrm{dm}^{-3}\right)$ and then they were ultrasonicated at RT for $1 \mathrm{~h}$, they were evaporated to dryness at $100^{\circ} \mathrm{C}$ for $2 \mathrm{~h}$ in air. The resultant solids were heat-treated at $200^{\circ} \mathrm{C}$ for $2 \mathrm{~h} \mathrm{in} \mathrm{H}_{2}$ to obtain metallic nanoparticles on the oxide surface. The obtained oxide powders loaded with noble metal $(\mathrm{N})$ were denoted as $n \mathrm{~N} / \mathrm{MO}[n$ : amount of noble metal $(\mathrm{N}$ : Pd or Pt), 0.03-0.10 (wt\%)]. Specific surface area of the $n \mathrm{~N} / \mathrm{MO}$ powders obtained was hardly influenced by the loading of the noble-metal nanoparticles (e.g., specific surface area of $0.05 \mathrm{Pd} / \mathrm{SnO}_{2}$ powder: ca. $21.0 \mathrm{~m}^{2} \mathrm{~g}^{-1}$ ), because the amount of noble-metal loading onto the oxide surface was really small $(\leq 0.10 \mathrm{wt} \%)$

Chemical states of the noble metal $(\mathrm{Pd}$ or $\mathrm{Pt})$ on the surface of representative $n \mathrm{~N} / \mathrm{MO}$ powders were characterized by X-ray photoelectron spectroscopy using $\mathrm{Mg} \mathrm{K} \alpha$ radiation (XPS, Kratos, ACIS-TLATRA DLD), and the binding energy was calibrated using the C 1s level $(285.0 \mathrm{eV})$ from usual contamination. Optical properties of representative oxide powders $\left(\mathrm{SnO}_{2}\right.$ and $0.05 \mathrm{Pd} / \mathrm{SnO}_{2}$ ) were investigated by ultraviolet (UV)-visible (Vis) spectrophotometer (JASCO Corp., V-650) with an integrated sphere (JASCO Corp., ISV-722).

\subsection{Fabrication of thick film sensors and measurement of their gas-sensing properties}

Thick film sensors were fabricated by screen printing employing the paste of each oxide powder on an alumina substrate equipped with a pair of interdigitated Pt electrodes (gap size: 
ca. $500 \mu \mathrm{m})$, followed by calcination at $500^{\circ} \mathrm{C}$ for $1 \mathrm{~h}$ in ambient air. The top-view photograph of a representative sensor element, $0.05 \mathrm{Pd} / \mathrm{SnO}_{2}$ sensor, is shown in Fig. 1(a). A thick film sensor was set in a test chamber with a temperature-controlled stage (Lincam Scientific Instr., LST420), which was connected with gas-flow system, and gas responses of these sensors were measured to $5 \mathrm{ppm} \mathrm{NO}_{2}$ balanced with dry or wet (relative humidity (RH): $20-80 \%$ ) air at $30^{\circ} \mathrm{C}$ at a flow rate of $100 \mathrm{~cm}^{3} \mathrm{~min}^{-1}$ under UV-light irradiation by using light-emitting diode (UVLED, Asahi Spectra Co., Ltd., POT-365, main wavelength: 365 nm, irradiation intensity: 0.8$134 \mathrm{~mW} \mathrm{~cm}^{-2}$ ), after pre-heat treatment at $200^{\circ} \mathrm{C}$ for several tens of minutes in dry or wet air. The experimental setup for gas-sensing measurements under UV-light irradiation is shown in Fig. 1(b). The magnitude of response to $\mathrm{NO}_{2}$ was defined as the ratio $\left(R_{\mathrm{NO}_{2}} / R_{\mathrm{a}}\right)$ of sensor resistance in $\mathrm{NO}_{2}$ balanced with air $\left(R_{\mathrm{NO}_{2}}\right)$ to that in $\operatorname{air}\left(R_{\mathrm{a}}\right)$. The $l \%$ response time $\left(T_{\mathrm{RS}}(l)\right)$ were defined as a period necessary to reach $l \%$ value of the resistance change $\left(\log R_{\mathrm{NO}_{2}}-\log R_{\mathrm{a}}\right)$ from the logarithm of sensor resistance in a base gas $(\log R \mathrm{a})$ to that that in $\mathrm{NO}_{2}$ balanced with air ( $\log R_{\mathrm{NO}_{2}}$, generally after 15 min from the injection of $\mathrm{NO}_{2}$ in air). The $m \%$ recovery time $\left(T_{\mathrm{RC}}(m)\right)$ were defined as a period necessary to reach $(100-m) \%$ value of the resistance change $\left(\log R_{\mathrm{NO}_{2}}-\log R_{\mathrm{a}}\right.$ ) after the injection of $\mathrm{NO}_{2}$ in air was stopped. The response and recovery times contain a delay period from the gas-switching time to the response- and recovery-starting times, ca. $1.2 \mathrm{~min}$, in this study, since the dead volume of the gas-flow pathway and the chamber in the measurement apparatus is ca. $106 \mathrm{~cm}^{3}$.

\section{Results and Discussion}

\section{1 $\mathrm{NO}_{2}$-sensing properties of unloaded oxide sensors under UV-light irradiation}

Figure 2 shows response transients of a $\mathrm{SnO}_{2}$ sensor to $5 \mathrm{ppm} \mathrm{NO}_{2}$ in dry air at $30^{\circ} \mathrm{C}$ under different UV-light irradiation intensities. Response transients of $\mathrm{In}_{2} \mathrm{O}_{3}$ and $\mathrm{WO}_{3}$ sensors to 5 ppm $\mathrm{NO}_{2}$ in dry air at $30^{\circ} \mathrm{C}$ under different UV-light irradiation intensities were also shown in 
Fig. $\mathrm{S} 1$, and variations in their responses $\left(R_{\mathrm{NO}_{2}} / R_{\mathrm{a}}\right)$ to $5 \mathrm{ppm} \mathrm{NO}$, resistances in dry air $\left(R_{\mathrm{a}}\right)$, and $90 \%$ response and $10 \%$ recovery times $\left(T_{\mathrm{RS}}(90)\right.$ and $T_{\mathrm{RC}}(10)$, respectively) with UV-light intensity were summarized in Fig. 3. In addition, typical sensing characteristics of these sensors were shown in Table 1. The resistance of the $\mathrm{SnO}_{2}$ sensor under no UV-light irradiation was relatively large in dry air $\left(R_{\mathrm{a}}\right.$ : ca. $\left.2.5 \times 10^{5} \Omega\right)$, since $\mathrm{SnO}_{2}$ was a typical n-type semiconducting oxide and the density of electron carriers was relatively low at $30^{\circ} \mathrm{C}[13-15,24,25,30-32]$. In addition, the $\mathrm{SnO}_{2}$ sensor showed a large positive $\mathrm{NO}_{2}$ response (ca. 81) under no UV-light irradiation. The behavior indicates that a large amount of $\mathrm{NO}_{2}$ molecules negatively chemisorbed as $\mathrm{NO}_{2}^{-}$on the $\mathrm{SnO}_{2}$ surface, trapping electron from the $\mathrm{SnO}_{2}$ bulk [13-15]. However, the response speed was really slow $\left(T_{\mathrm{RS}}(90)\right.$ : ca. $\left.12 \mathrm{~min}\right)$ and the sensor showed little recovery behavior $\left(T_{\mathrm{RC}}(10)\right.$ : ca. $\left.30 \mathrm{~min}\right)$. Weak UV-light irradiation abruptly decreased the resistance of the $\mathrm{SnO}_{2}$ sensor in dry air (e.g., $R_{\mathrm{a}}$ : ca. $1.2 \times 10^{4} \Omega$ at $7 \mathrm{~mW} \mathrm{~cm}^{-2}$ ) and the further increase in the UV-light intensity decreased the resistance gradually, because the UV-light irradiation excited electrons in the $\mathrm{SnO}_{2}$ bulk to the conduction band and/or it reduced negatively oxygen adsorbates (mainly, $\mathrm{O}_{2}^{-}$) on the $\mathrm{SnO}_{2}$ surface $[25,33]$. The $\mathrm{NO}_{2}$ response of the $\mathrm{SnO}_{2}$ sensor under weak UV-light irradiation (especially, $\leq 7 \mathrm{~mW} \mathrm{~cm}^{-2}$ ) was much larger than that under no UV-light irradiation, but the further increase in the UV-light intensity (more than $35 \mathrm{~mW} \mathrm{~cm}^{-2}$ ) decreased the $\mathrm{NO}_{2}$ response, in comparison with that under no UV-light irradiation. The response speed was hardly improved by the weakest UV-light irradiation $(0.8$ $\left.\mathrm{mW} \mathrm{cm}{ }^{-2}\right)$. The further increase in the UV-light intensity $\left(\geq 7 \mathrm{~mW} \mathrm{~cm}^{-2}\right)$ was quite effective in reducing the response time, but the response time was less dependent on the UV-light intensity in the range between $7 \mathrm{~mW} \mathrm{~cm}^{-2}$ and $134 \mathrm{~mW} \mathrm{~cm}^{-2}$. On the other hand, the recovery speed was relatively improved even by the weakest UV-light irradiation $\left(T_{\mathrm{RC}}(10)\right.$ : ca. $5.1 \mathrm{~min}$ at $0.8 \mathrm{~mW}$ $\mathrm{cm}^{-2}$ ), and the further increase in UV-light intensity tended to reduce the recovery time, probably because the UV-light irradiation promoted the desorption of $\mathrm{NO}_{2}{ }^{-}$on the $\mathrm{SnO}_{2}$ surface. 
However, even strong UV-light irradiation was not able to turn the resistance in dry air back to the original level before the $\mathrm{NO}_{2}$ injection, during the measurement period. These facts indicate that the injection of photon energy into the $\mathrm{SnO}_{2}$ was effective in enhancing chemical adsorption/desorption of $\mathrm{NO}_{2}$ on the $\mathrm{SnO}_{2}$ surface and the balance between adsorption and desorption of $\mathrm{NO}_{2}$ probably determined not only the magnitude of $\mathrm{NO}_{2}$ response but also the response and recovery speeds.

The effects of UV-light irradiation on the $\mathrm{NO}_{2}$-sensing properties of $\mathrm{In}_{2} \mathrm{O}_{3}$ and $\mathrm{WO}_{3}$ sensors are fundamentally similar to those of the $\mathrm{SnO}_{2}$ sensor, but some important behavior was different among them. The resistance of both the sensors decreased with an increase in UV-light intensity, as is the case with that of the $\mathrm{SnO}_{2}$ sensor. The resistance of the $\mathrm{In}_{2} \mathrm{O}_{3}$ sensor was smaller than that of the $\mathrm{SnO}_{2}$ sensor, while the resistance of the $\mathrm{WO}_{3}$ sensor was larger that of the $\mathrm{SnO}_{2}$ sensor, with or without UV-light irradiation. The $\mathrm{In}_{2} \mathrm{O}_{3}$ sensor showed the largest $\mathrm{NO}_{2}$ response among all the pristine oxide sensors when UV light was not irradiated. However, even weak UV-light irradiation largely reduced the $\mathrm{NO}_{2}$ response of the $\mathrm{In}_{2} \mathrm{O}_{3}$ sensor and the $\mathrm{NO}_{2}$ response decreased with an increase in UV-light intensity. Thus, the $\mathrm{NO}_{2}$ response of the $\mathrm{In}_{2} \mathrm{O}_{3}$ sensor under UV-light irradiation was much smaller than that of the $\mathrm{SnO}_{2}$ sensor. The dependence of response and recovery speeds of the $\operatorname{In}_{2} \mathrm{O}_{3}$ sensor on UV-light intensity was also quite similar to those of the $\mathrm{SnO}_{2}$ sensor, and the UV-light irradiation was effective in reducing the response and recovery times. On the other hand, the $\mathrm{NO}_{2}$ response of the $\mathrm{WO}_{3}$ sensor was not able to be confirmed under no UV-light irradiation, because the resistance in $5 \mathrm{ppm} \mathrm{NO}_{2}$ balanced with dry air was too high to be measured with the measurement apparatus used in this study. However, the magnitude of $\mathrm{NO}_{2}$ response of the $\mathrm{WO}_{3}$ sensor under no UV-light irradiation was over 900, which was larger than that of the $\mathrm{SnO}_{2}$ sensor. The large $\mathrm{NO}_{2}$ response of the $\mathrm{WO}_{3}$ sensor under no UV-light irradiation in comparison with other oxide sensors has already been reported by several researchers [19-22]. The UV-light irradiation drastically 
reduced the $\mathrm{NO}_{2}$ response, and the $\mathrm{NO}_{2}$ response of the $\mathrm{WO}_{3}$ sensor under UV-light irradiation was the smallest among all the sensors under all the UV-light irradiation range. The response and recovery speeds under no UV-light irradiation were not also be calculated because of too high resistance in $5 \mathrm{ppm} \mathrm{NO}_{2}$ balanced with dry air beyond the range of measurement, and thus the effect of the UV-light irradiation on the response and recovery speeds was not able to be discussed in this study. However, the response and recovery speeds of the $\mathrm{WO}_{3}$ sensor even under UV-light irradiation were much slower than those of the $\mathrm{SnO}_{2}$ and $\operatorname{In}_{2} \mathrm{O}_{3}$ sensors. These results indicate that the $\mathrm{WO}_{3}$ sensor, which generally shows large $\mathrm{NO}_{2}$ response at elevated temperatures, is not suitable for detecting $\mathrm{NO}_{2}$ at $\mathrm{RT}$ under UV-light irradiation. Considering the above results based on the impacts of the UV-light intensity on the magnitude of their $\mathrm{NO}_{2}$ responses, we should investigate the $\mathrm{NO}_{2}$-sensing properties of these sensors under much weaker UV-light irradiation, but such weak UV-light irradiation $\left(<0.8 \mathrm{~mW} \mathrm{~cm}^{-2}\right)$ is out of control for our experimental setup. In addition, the too slow response and recovery speeds of the $\mathrm{WO}_{3}$ sensor under weak UV-light irradiation presently make our interests go away from the investigation in this study, especially from the aspect of the practice use. As mentioned above, the $\mathrm{WO}_{3}$ sensor as well as the $\mathrm{In}_{2} \mathrm{O}_{3}$ sensor showed smaller $\mathrm{NO}_{2}$ responses under UV-light irradiation at ca. $365 \mathrm{~nm}$ in this study, than that of the $\mathrm{SnO}_{2}$ sensor. However, the $\mathrm{In}_{2} \mathrm{O}_{3}$ and $\mathrm{WO}_{3}$ sensors may be able to detect $\mathrm{NO}_{2}$ and other gases more sensitively under visible-light irradiation in comparison with the $\mathrm{SnO}_{2}$ sensor, because the band gaps of $\mathrm{In}_{2} \mathrm{O}_{3}$ [28] and $\mathrm{WO}_{3}$ [29] were generally lower than that of $\mathrm{SnO}_{2}$. The impacts of wavelength of irradiated light on the gas-sensing properties of these sensors will be investigated in the near future.

\subsection{Effects of Pd loading onto $\mathrm{SnO}_{2}$ and $\mathrm{In}_{2} \mathrm{O}_{3}$ sensors on their $\mathrm{NO}_{2}$-sensing properties}

Effects of Pd loading onto both the $\mathrm{SnO}_{2}$ and $\mathrm{In}_{2} \mathrm{O}_{3}$ sensors, which showed much excellent $\mathrm{NO}_{2}$-sensing properties and relatively lower resistance in dry air under UV-light irradiation than 
the $\mathrm{WO}_{3}$ sensor, on the $\mathrm{NO}_{2}$-sensing properties were investigated in this study. Figure 4 shows response transients of representative $n \mathrm{Pd} / \mathrm{SnO}_{2}$ sensors ( $n: 0.05$ and 0.07 ) to $5 \mathrm{ppm} \mathrm{NO}_{2}$ at $30^{\circ} \mathrm{C}$ in dry air under different UV-light irradiation intensities. In addition, Fig. 5 shows variations in response to $5 \mathrm{ppm} \mathrm{NO} 2$ and resistance of all $n \mathrm{Pd} / \mathrm{SnO}_{2}$ sensors in dry air with the amount of $\mathrm{Pd}$ loaded, and Fig. S2 shows variations in $90 \%$ response and $60 \%$ recovery times of all $n \mathrm{Pd} / \mathrm{SnO}_{2}$ sensors with UV-light intensity, together with those of the $\mathrm{SnO}_{2}$ sensor. Typical sensing characteristics of the $0.05 \mathrm{Pd} / \mathrm{SnO}_{2}$ sensor were shown also in Table 1 . Here, the resistance of most of $n \mathrm{Pd} / \mathrm{SnO}_{2}$ sensors under no UV-light irradiation was instable in $5 \mathrm{ppm} \mathrm{NO}_{2}$ balanced with dry air, and the $\mathrm{NO}_{2}$-sensing property of only the $0.05 \mathrm{Pd} / \mathrm{SnO}_{2}$ sensor was able to be measured under no UV-light irradiation. The $\mathrm{Pd}$ loading onto the $\mathrm{SnO}_{2}$ surface increased the resistance in dry air with or without UV-light irradiation. It is well known that Pd nanoparticles are oxidized by heat treatment at elevated temperatures in air [34-36]. Therefore, XPS spectra of $\mathrm{Pd}$ on the surface of representative $n \mathrm{Pd} / \mathrm{SnO}_{2}$ powders $(n: 0.05$ and 0.10$)$ after the heat treatment at $500^{\circ} \mathrm{C}$ for $1 \mathrm{~h}$ in ambient air, which is the same heat-treatment condition as the sensor fabrication, were investigated as shown in Fig. 6. The obtained XPS spectra of Pd $3 \mathrm{~d}_{5 / 2}$ and $3 \mathrm{~d}_{3 / 2}$ obviously exhibited that the heat treatment at $500^{\circ} \mathrm{C}$ oxidized almost all $\mathrm{Pd}$ nanoparticles on the surface of $0.05 \mathrm{Pd} / \mathrm{SnO}_{2}$ and $0.10 \mathrm{Pd} / \mathrm{SnO}_{2}$ powders, to form $\mathrm{PdO}$ [36]. The electron affinity of $\mathrm{PdO}$ (ca. $5.5 \mathrm{eV}$ ) [34] are larger than that of $\mathrm{SnO}_{2}(\mathrm{ca} .4 .5 \mathrm{eV})$ [37, 38], and therefore electrons of $\mathrm{SnO}_{2}$ are likely transferred into the $\mathrm{PdO}$ nanoparticles. This is the reason why the resistance of $n \mathrm{Pd} / \mathrm{SnO}_{2}$ sensors in dry air increased with an increase in the amount of Pd loading, as shown in Fig. 5(b). In addition, the resistance of all the $n \mathrm{Pd} / \mathrm{SnO}_{2}$ sensors monotonically decreased with an increase in UV-light intensity, as is the case with the $\mathrm{SnO}_{2}$ sensor. The Pd loading effectively enhanced the $\mathrm{NO}_{2}$ response of the $\mathrm{SnO}_{2}$ sensor, probably because the large amount of $\mathrm{NO}_{2}$ molecules directly adsorbed on the surface of $\mathrm{PdO}$ nanoparticles and $\mathrm{SnO}_{2}$ and/or the $\mathrm{NO}_{2}$ species adsorbed on the $\mathrm{PdO}$ surface spilt over onto the 
$\mathrm{SnO}_{2}$ surface. The UV-light irradiation drastically changed their response behavior to $5 \mathrm{ppm}$ $\mathrm{NO}_{2}$ at $30^{\circ} \mathrm{C}$ in dry air. Namely, all the $n \mathrm{Pd} / \mathrm{SnO}_{2}$ sensors showed the largest $\mathrm{NO}_{2}$ response under UV-light irradiation of $7 \mathrm{~mW} \mathrm{~cm}^{-2}$ (ca. $3.4 \times 10^{3}$ for $0.05 \mathrm{Pd} / \mathrm{SnO}_{2}$ ), their $\mathrm{NO}_{2}$ responses decreased with an increase in the UV-light intensity, regardless of the amount of Pd loaded onto the $\mathrm{SnO}_{2}$ surface, and thus the $\mathrm{NO}_{2}$ responses of $\mathrm{SnO}_{2}$ and $0.05 \mathrm{Pd} / \mathrm{SnO}_{2}$ sensors under strong UV-light irradiation of 75 and $134 \mathrm{~mW} \mathrm{~cm}^{-2}$ was lower than those under no UV-light irradiation. Then, the $0.05 \mathrm{Pd} / \mathrm{SnO}_{2}$ sensor showed the largest $\mathrm{NO}_{2}$ response among all the sensors at every UV-light intensity. The $0.05 \mathrm{Pd} / \mathrm{SnO}_{2}$ sensor, which only had relatively stable $\mathrm{NO}_{2}$ response among all the $n \mathrm{Pd} / \mathrm{SnO}_{2}$ sensors under no UV-light irradiation, showed quite slow response speed without recovery behavior under no UV-light irradiation, as is the case with the $\mathrm{SnO}_{2}$ sensor. The weak UV-light irradiation stabilized the $\mathrm{NO}_{2}$-response behavior of the $n \mathrm{Pd} / \mathrm{SnO}_{2}$ sensors and drastically accelerated the response speeds of all the $n \mathrm{Pd} / \mathrm{SnO}_{2}$ sensors to $\mathrm{NO}_{2}$ (e.g., $T_{\mathrm{RS}}(90)$ : ca. $2.8 \mathrm{~min}$ for the $0.05 \mathrm{Pd} / \mathrm{SnO}_{2}$ sensor at $7 \mathrm{~mW} \mathrm{~cm}^{-2}$ ), but the further increase in UVlight irradiation tended to slow down the response speeds (e.g., $T_{\mathrm{RS}}(90)$ : ca. $6.7 \mathrm{~min}$ for the $0.05 \mathrm{Pd} / \mathrm{SnO}_{2}$ sensor at $134 \mathrm{~mW} \mathrm{~cm}^{-2}$ ). On the other hand, an increase in UV-light irradiation tended to improve the recovery speeds of all the $n \mathrm{Pd} / \mathrm{SnO}_{2}$ sensors to $\mathrm{NO}_{2}$ (e.g., $T_{\mathrm{RC}}(60)$ : ca. $5.5 \mathrm{~min}$, for the $0.05 \mathrm{Pd} / \mathrm{SnO}_{2}$ sensor at $134 \mathrm{~mW} \mathrm{~cm}^{-2}$ ).

The resistance change of $\mathrm{SnO}_{2}$ and $0.05 \mathrm{Pd} / \mathrm{SnO}_{2}$ sensors with $\mathrm{O}_{2}$ injection into dry $\mathrm{N}_{2}$ was investigated at $30^{\circ} \mathrm{C}$ with and without UV-light irradiation, to clarify the effects of adsorption and desorption of oxygen species on their resistances. Figure 7 shows representative response transients of the $\mathrm{SnO}_{2}$ and $0.05 \mathrm{Pd} / \mathrm{SnO}_{2}$ sensors to $30 \% \mathrm{O}_{2}$ in dry $\mathrm{N}_{2}$ at $30^{\circ} \mathrm{C}$ and variations in response of these sensors to $30 \% \mathrm{O}_{2}$ in dry $\mathrm{N}_{2}$ at $30^{\circ} \mathrm{C}$ with UV-light intensity. The magnitude of response to $30 \% \mathrm{O}_{2}$ in dry $\mathrm{N}_{2}$ was defined as the ratio of sensor resistance in $30 \% \mathrm{O}_{2}$ balanced with dry $\mathrm{N}_{2}$ (after 70 min upon exposure to $\mathrm{O}_{2}$ ) to that in dry $\mathrm{N}_{2}$. These sensors were heattreated in dry $\mathrm{N}_{2}$ at $200^{\circ} \mathrm{C}$ for $2 \mathrm{~h}$, prior to the measurement, to remove oxygen species $\left(\mathrm{O}_{2}^{-}\right)$ 
which are adsorbed on the $\mathrm{SnO}_{2}$ surface. The resistance of the $\mathrm{SnO}_{2}$ sensor was smaller than that of the $0.05 \mathrm{Pd} / \mathrm{SnO}_{2}$ sensor even in dry $\mathrm{N}_{2}$ with or without UV-light irradiation, and the UVlight irradiation reduced these resistances in dry $\mathrm{N}_{2}$, as is the cases in dry air. These facts under the $\mathrm{O}_{2}$-free atmosphere strongly supports that electrons in $\mathrm{SnO}_{2}$ and $0.05 \mathrm{Pd} / \mathrm{SnO}_{2}$ bulk excited from valence band and/or some defect levels to the conduction band by the UV-light irradiation, because most of oxygen species $\left(\mathrm{O}_{2}^{-}\right)$on their surface should be desorbed by the pre-heat treatment in $\mathrm{N}_{2}$ at $200^{\circ} \mathrm{C}$. Figure 8 shows diffuse reflectance UV-Vis spectra (normalized Kubelka-Munk function $\left(F(r) / F(r)_{\mathrm{MAX}}\right) v s$. wavelength, where $r$ stands for reflectance and $F(r)$ MAx is the maximum of Kubelka-Munk function $(F(r)))$ of $\mathrm{SnO}_{2}$ and $0.05 \mathrm{Pd} / \mathrm{SnO}_{2}$ powders, together with their Tarc plots $\left((h v F(r))^{2} v s\right.$. photon energy, where $h$ and $v$ stand for Plank constant and frequency, respectively [39]). Band gaps $\left(E_{\mathrm{g}}\right)$ of $\mathrm{SnO}_{2}$ and $0.05 \mathrm{Pd} / \mathrm{SnO}_{2}$, which was determined from the Tarc plots, were ca. $3.5 \mathrm{eV}$ and ca. $3.7 \mathrm{eV}$, respectively, which were closely correspondent with those of typical $\mathrm{SnO}_{2}, 3.4-3.8 \mathrm{eV}[38,40,41]$. The difference in $E_{\mathrm{g}}$ between $\mathrm{SnO}_{2}$ and $0.05 \mathrm{Pd} / \mathrm{SnO}_{2}$ probably depends on whether or not $\mathrm{PdO}$ nanoparticles were loaded onto their surfaces and/or they were heat-treated at $200^{\circ} \mathrm{C}$ under $\mathrm{H}_{2}$ atmosphere. Since the band-gap energies of $\mathrm{SnO}_{2}$ and $0.05 \mathrm{Pd} / \mathrm{SnO}_{2}$ powders are slightly larger than main photon energy of UV light emitted from the UV-LED (ca. $3.40 \mathrm{eV}$, which was calculated from the main wavelength, $365 \mathrm{~nm}$ ), electrons in valence band cannot easily excite to the conduction band. However, the optical absorption edge up to the range of visible light (i.e., $>400 \mathrm{~nm}$ ) was observed for the $\mathrm{SnO}_{2}$ and $0.05 \mathrm{Pd} / \mathrm{SnO}_{2}$ powders, which are pale yellow and pale brown, respectively, in Fig. 8. The absorption probably arises from some energy levels of various defects such as oxygen vacancies [40], since these powders were prepared under relatively moderate condition (at $600^{\circ} \mathrm{C}$ for $1 \mathrm{~h}$ in ambient air). These optical properties are one of the reasons why the UV-light irradiation reduced even the resistance of both the sensors in dry $\mathrm{N}_{2}$ (see Fig. 7). The injection of $30 \% \mathrm{O}_{2}$ in dry $\mathrm{N}_{2}$ increased the resistance of both the sensors with 
or without UV-light irradiation, because oxygen species negatively adsorbed on the oxide surface, according to the forward reaction of the following equation [25, 33].

$$
\mathrm{O}_{2}+\mathrm{e}^{-} \rightleftarrows \mathrm{O}_{2}^{-}(\mathrm{ad})
$$

However, the resistances of both the sensors even after 70 min upon exposure to $30 \% \mathrm{O}_{2}$ in dry $\mathrm{N}_{2}$ (ca. $1.2 \times 10^{3} \Omega$ and ca. $3.0 \times 10^{4} \Omega$ for $\mathrm{SnO}_{2}$ and $0.05 \mathrm{Pd} / \mathrm{SnO}_{2}$ sensors, respectively) were much smaller than those in dry air $\left(21 \% \mathrm{O}_{2}\right)\left(\right.$ ca. $2.3 \times 10^{5} \Omega$ and ca. $4.0 \times 10^{5} \Omega$ for $\mathrm{SnO}_{2}$ and 0.05Pd/SnO 2 sensors, respectively, cf. Figs. 2-5) under no UV-light irradiation. On the other hand, the UV-light irradiation improved the rate of resistance change of both the sensors. Namely, the resistance of the $\mathrm{SnO}_{2}$ sensor after 70 min upon exposure to $30 \% \mathrm{O}_{2}$ in dry $\mathrm{N}_{2}$ under UV-light irradiation (e.g., ca. $7.9 \times 10^{2} \Omega$ at $134 \mathrm{~mW} \mathrm{~cm}^{-2}$ ) was slightly smaller than those in dry $\operatorname{air}\left(21 \% \mathrm{O}_{2}\right)$ (e.g., ca. $3.2 \times 10^{3} \Omega$ at $\left.134 \mathrm{~mW} \mathrm{~cm}^{-2}\right)$ and the resistance of the $0.05 \mathrm{Pd} / \mathrm{SnO}_{2}$ sensor after 70 min upon exposure to $30 \% \mathrm{O}_{2}$ in dry $\mathrm{N}_{2}$ under UV-light irradiation (e.g., ca. $4.5 \times 10^{3} \Omega$ at $\left.134 \mathrm{~mW} \mathrm{~cm}^{-2}\right)$ was already larger than those in dry air $\left(21 \% \mathrm{O}_{2}\right)\left(\right.$ e.g., ca. $4.0 \times 10^{3}$ $\Omega$ at $134 \mathrm{~mW} \mathrm{~cm}^{-2}$ ). These results obviously show that the UV-light irradiation enhanced the rate of the forward reaction of the eq. (1), producing the large amount of negatively adsorbed oxygen species $\left(\mathrm{O}_{2}{ }^{-}\right)$. In addition, the behavioral difference between these sensors indicates that $\mathrm{PdO}$ nanoparticles on the $\mathrm{SnO}_{2}$ surface accelerated the adsorption of $\mathrm{O}_{2}^{-}$onto the surface and the adsorption rate of oxygen species on the $\mathrm{PdO}$ surface (and/or the amounts) was larger than that on the $\mathrm{SnO}_{2}$ surface. Furthermore, the UV-light irradiation drastically accelerated also the desorption rate of negatively adsorbed oxygen species (i.e., the reverse reaction of eq. (1)), on the basis that the resistances of both the sensors smoothly decreased after the injection of $\mathrm{O}_{2}$ in dry $\mathrm{N}_{2}$ was stopped. However, large $\mathrm{NO}_{2}$ responses of the $\mathrm{SnO}_{2}$ and $0.05 \mathrm{Pd} / \mathrm{SnO}_{2}$ sensors with their fast response speed and slow recovery speed in dry air (see Figs. 2-4 and S2) shows that $\mathrm{NO}_{2}$ molecules promptly adsorbed even onto the oxide surface which was covered with $\mathrm{O}_{2}^{-}$ adsorbed, according to the forward reaction of the following equation [24, 42]. 


$$
\mathrm{NO}_{2}+\mathrm{e}^{-} \rightleftarrows \mathrm{NO}_{2}^{-}(\mathrm{ad})
$$

In summary, the forward reaction of the following equation promptly proceeds even in a low concentration $(5 \mathrm{ppm})$ of $\mathrm{NO}_{2}$ balanced with dry air $\left(21 \% \mathrm{O}_{2}\right)$, probably because the adsorption energy of $\mathrm{NO}_{2}$ onto the surface (eq. (2)) is much larger than that of $\mathrm{O}_{2}$ (eq. (1)).

$$
\mathrm{NO}_{2}+\mathrm{O}_{2}^{-}(\mathrm{ad}) \rightleftarrows \mathrm{NO}_{2}^{-}(\mathrm{ad})+\mathrm{O}_{2}
$$

In addition, Ruhland et al. reported that physisorbed $\mathrm{NO}_{2}$ molecules form deeper acceptor levels on the $\mathrm{SnO}_{2}$ surface than negatively adsorbed oxygen species $\left(\mathrm{O}_{2}{ }^{-}\right)$, and thus bound electrons are transferred from the $\mathrm{O}_{2}{ }^{-}$to physisorbed $\mathrm{NO}_{2}$ molecules forming $\mathrm{NO}_{2}^{-}$species [43]. The deep acceptor levels which are formed by $\mathrm{NO}_{2}{ }^{-}$species on the oxide surface is the main reason of large resistances of the sensors in $\mathrm{NO}_{2}$ balanced with dry air. Furthermore, Fig. 7 shows the response of the $0.05 \mathrm{Pd} / \mathrm{SnO}_{2}$ sensor to $30 \% \mathrm{O}_{2}$ was larger than that of the $\mathrm{SnO}_{2}$ sensor in dry $\mathrm{N}_{2}$ and the recovery speed of the $0.05 \mathrm{Pd} / \mathrm{SnO}_{2}$ sensor was faster than that of the $\mathrm{SnO}_{2}$ sensor. This is probably because $\mathrm{PdO}$ nanoparticles on the $\mathrm{SnO}_{2}$ surface accelerated the adsorption and desorption of $\mathrm{O}_{2}$, which is one of important factors in determining faster response and recovery speeds of the $0.05 \mathrm{Pd} / \mathrm{SnO}_{2}$ sensor to $\mathrm{NO}_{2}$ than that of the $\mathrm{SnO}_{2}$ sensor.

On the other hand, an increase in UV-light intensity reduced the magnitude of $\mathrm{NO}_{2}$ response of these sensors. It is well known that $\mathrm{NO}_{2}$ was converted to $\mathrm{NO}$ and atomic oxygen under UVlight irradiation, according to the following reaction [44].

$$
\mathrm{NO}_{2}+h v \rightarrow \mathrm{NO}+\mathrm{O}
$$

In addition, an increase in UV-light intensity reduces the amount of adsorbed $\mathrm{NO}_{2}^{-}$on the oxide surface, and thus accelerates the reverse reaction of eq. (2). It is expected that these reactions were promoted with increasing UV-light intensity to decrease the $\mathrm{NO}_{2}$ response of these sensors. Furthermore, an increase in UV-light intensity improved the response and recovery speeds of both the sensors, because the rates of adsorption and desorption of $\mathrm{O}_{2}$ and $\mathrm{NO}_{2}$ increased with increasing UV-light intensity. 
Figure $\mathrm{S} 3$ shows response transients of $0.05 \mathrm{Pd} / \mathrm{In}_{2} \mathrm{O}_{3}$ and $0.07 \mathrm{Pd} / \mathrm{In}_{2} \mathrm{O}_{3}$ sensors to $5 \mathrm{ppm} \mathrm{NO} \mathrm{NO}_{2}$ at $30^{\circ} \mathrm{C}$ in dry air under different UV-light irradiation intensities, and Fig. S4 shows variations in response of these sensors to $5 \mathrm{ppm} \mathrm{NO}_{2}$ and resistance in dry air with the amount of Pd loaded and UV-light intensity, respectively. In addition, an XPS spectrum of $\mathrm{Pd} 3 \mathrm{~d}_{5 / 2}$ and $3 \mathrm{~d}_{3 / 2}$ on the surface of representative $n \mathrm{Pd} / \mathrm{In}_{2} \mathrm{O}_{3}$ powder $(n: 0.07)$ after heat treatment at $500^{\circ} \mathrm{C}$ for $1 \mathrm{~h} \mathrm{in}$ ambient air is shown in Fig. S5. The XPS spectrum of Pd was quite similar to those of $0.05 \mathrm{Pd} / \mathrm{SnO}_{2}$ and $0.10 \mathrm{Pd} / \mathrm{SnO}_{2}$ powders (Fig. 6), which indicates that most of the $\mathrm{Pd}$ nanoparticles loaded on the $0.07 \mathrm{Pd} / \mathrm{In}_{2} \mathrm{O}_{3}$ powder were also oxidized to form $\mathrm{PdO}$ [36]. The resistance in dry air increased with an increase in the amount of Pd loaded onto $\operatorname{In}_{2} \mathrm{O}_{3}$, because of smaller electron affinity of $\mathrm{In}_{2} \mathrm{O}_{3}(\mathrm{ca} .3 .7 \mathrm{eV})$ [45] than the electron affinity of $\mathrm{PdO}$, and it decreased with an increase in UV-light intensity, as is the case with the $n \mathrm{Pd} / \mathrm{SnO}_{2}$ sensors. However, even the response of the $0.05 \mathrm{Pd} / \mathrm{In}_{2} \mathrm{O}_{3}$ sensor to $5 \mathrm{ppm} \mathrm{NO}_{2}$ under UV-light irradiation of $7 \mathrm{~mW} \mathrm{~cm}^{-2}$ (ca. 38), which was the largest among those of the $n \mathrm{Pd} / \mathrm{In}_{2} \mathrm{O}_{3}$ sensors, was much smaller than that of the $0.05 \mathrm{Pd} / \mathrm{SnO}_{2}$ sensor $\left(R_{\mathrm{NO}_{2}} / R_{\mathrm{a}}\right.$ : ca. $\left.3.4 \times 10^{3}\right)$. The response times of the $n \mathrm{Pd} / \mathrm{In}_{2} \mathrm{O}_{3}$ sensors (e.g., $T_{\mathrm{RS}}(90)$ : ca. $3.2 \mathrm{~min}$ and ca. $3.0 \mathrm{~min}$ for the $0.05 \mathrm{Pd} / \mathrm{In}_{2} \mathrm{O}_{3}$ sensor at 7 and $134 \mathrm{~mW} \mathrm{~cm}^{-2}$, respectively) were comparable to (or faster than, in some cases) those of the $n \mathrm{Pd} / \mathrm{SnO}_{2}$ sensors (e.g., $T_{\mathrm{RS}}(90)$ : ca. $2.8 \mathrm{~min}$ and ca. $6.8 \mathrm{~min}$ for the $0.05 \mathrm{Pd} / \mathrm{SnO}_{2}$ sensor at 7 and $134 \mathrm{~mW} \mathrm{~cm}^{-2}$, respectively), while the recovery times of the $n \mathrm{Pd} / \mathrm{In}_{2} \mathrm{O}_{3}$ sensors (e.g., $T_{\mathrm{RC}}(60)$ : ca. $37 \mathrm{~min}$ and ca. $30 \mathrm{~min}$ for the $0.05 \mathrm{Pd} / \mathrm{In}_{2} \mathrm{O}_{3}$ and $0.07 \mathrm{Pd} / \mathrm{In}_{2} \mathrm{O}_{3}$ sensors at 7 $\mathrm{mW} \mathrm{cm}{ }^{-2}$, respectively) were much longer to those of the $n \mathrm{Pd} / \mathrm{SnO}_{2}$ sensors (e.g., $T_{\mathrm{RC}}(60)$ ): ca. $16 \mathrm{~min}$ and ca. $17 \mathrm{~min}$ for the $0.05 \mathrm{Pd} / \mathrm{SnO}_{2}$ and $0.07 \mathrm{Pd} / \mathrm{SnO}_{2}$ sensors at $7 \mathrm{~mW} \mathrm{~cm}{ }^{-2}$, respectively). These results show that the Pd loading was not effective in improving the $\mathrm{NO}_{2}$ sensing properties of the $\mathrm{In}_{2} \mathrm{O}_{3}$ sensor under UV-light irradiation at least, in comparison with those of the $\mathrm{SnO}_{2}$ sensor. Hereafter, the gas-sensing properties of the $n \mathrm{Pd} / \mathrm{In}_{2} \mathrm{O}_{3}$ sensors should be measured under visible-light irradiation, together with those of both the $\mathrm{In}_{2} \mathrm{O}_{3}$ and $\mathrm{WO}_{3}$ 
sensors as shown in Section 3.1, to clarify the potential as a light-driven gas sensor which can be operated in the vicinity of room temperature.

\subsection{Effects of Pt loading onto $\mathrm{SnO}_{2}$ sensor on the $\mathrm{NO}_{2}$-sensing properties}

Effects of Pt loading on the $\mathrm{NO}_{2}$-sensing properties of the $\mathrm{SnO}_{2}$ sensor were also investigated in this study. XPS spectra of $\mathrm{Pt} 4 \mathrm{f}_{7 / 2}$ and $4 \mathrm{f}_{5 / 2}$ on the surface of prepared $n \mathrm{Pt} / \mathrm{SnO}_{2}$ powders $(n$ : 0.05 and 0.10 ) after heat treatment at $500^{\circ} \mathrm{C}$ for $1 \mathrm{~h}$ in ambient air, which is the same heattreatment condition as the sensor fabrication, are shown in Fig. 9. A major majority of the Pt nanoparticles loaded on both the powders $(\sim 90 \%)$ was oxidized after the heat treatment, to turn into $\mathrm{PtO}_{2}$ and $\mathrm{PtO}\left(\mathrm{Pt}^{4+}: \mathrm{Pt}^{2+}: \mathrm{Pt}(\right.$ metal $)=50.9: 38.6: 10.5$ for $0.05 \mathrm{Pt} / \mathrm{SnO}_{2}$ and 57.5:33.3:9.2 for $0.10 \mathrm{Pt} / \mathrm{SnO}_{2}$ ) [46]. Figure $\mathrm{S} 6$ shows response transients of $0.05 \mathrm{Pt} / \mathrm{SnO}_{2}$ and $0.10 \mathrm{Pt} / \mathrm{SnO}_{2}$ sensors to $5 \mathrm{ppm} \mathrm{NO}_{2}$ at $30^{\circ} \mathrm{C}$ in dry air under UV-light irradiation, and Fig. 10 shows variations in response of these sensors to $5 \mathrm{ppm} \mathrm{NO}_{2}$ with UV-light intensity, together with those of the $\mathrm{SnO}_{2}, 0.05 \mathrm{Pd} / \mathrm{SnO}_{2}$ and $0.10 \mathrm{Pd} / \mathrm{SnO}_{2}$ sensors. In addition, typical sensing characteristics of the $0.05 \mathrm{Pt} / \mathrm{SnO}_{2}$ sensor were shown in Table 1 . The resistance of these sensors in dry air, which increased with an increase in the amount of Pt loaded onto $\mathrm{SnO}_{2}$, also decreased with an increase in UV-light intensity. The $0.05 \mathrm{wt} \% \mathrm{Pt}$ loading improved the $\mathrm{NO}_{2}$ response and the response speed of the $\mathrm{SnO}_{2}$ sensor under every UV-light irradiation intensity (e.g., $R \mathrm{NO}_{2} / R_{\mathrm{a}}$ : ca. $1.5 \times 10^{3}$ and $T_{\mathrm{RS}}(90)$ : ca. $3.2 \mathrm{~min}$ for the $0.05 \mathrm{Pt} / \mathrm{SnO}_{2}$ sensor at $7 \mathrm{~mW} \mathrm{~cm}{ }^{-2}$ ), but the effectiveness was smaller than that of the $0.05 \mathrm{wt} \%$ Pd loading, especially under higher UVlight irradiation. On the other hand, the $0.05 \mathrm{wt} \% \mathrm{Pt}$ loading was effective in improving only the recovery speed under every UV-light irradiation intensity ( e.g., $T_{\mathrm{RC}}(60)$ : ca. 13 and ca. 3.5 min for the $0.05 \mathrm{Pt} / \mathrm{SnO}_{2}$ sensor at 7 and $134 \mathrm{~mW} \mathrm{~cm}^{-2}$, respectively). However, an increase in the amount of Pt loading (i.e., $1.0 \mathrm{wt} \% \mathrm{Pt}$ loading) tended to slow down the response and recovery speeds as well as to reduce the $\mathrm{NO}_{2}$ response. These results indicate that the Pd loading 
onto the $\mathrm{SnO}_{2}$ surface was more effective in improving the $\mathrm{NO}_{2}$-sensing properties of the $\mathrm{SnO}_{2}$ sensor at $30^{\circ} \mathrm{C}$ in dry air under UV-light irradiation, than the Pt loading.

\subsection{Effects of humidity in gaseous atmosphere on the $\mathrm{NO}_{2}$-sensing properties of $\mathrm{SnO}_{2}$ and $0.05 \mathrm{Pd} / \mathrm{SnO}_{2}$ sensors}

Figure $\mathrm{S} 7$ shows representative response transients of $\mathrm{SnO}_{2}$ and $0.05 \mathrm{Pd} / \mathrm{SnO}_{2}$ sensors to 5 ppm $\mathrm{NO}_{2}$ in wet air $(80 \% \mathrm{RH})$, and Fig. 11 shows variations in response $\left(R_{\mathrm{NO}_{2}} / R_{\mathrm{a}}\right)$ of these sensors to $5 \mathrm{ppm} \mathrm{NO}_{2}$ in air at $30^{\circ} \mathrm{C}$ under different UV-light irradiation intensities with relative humidity. The addition of moisture into air drastically had great impacts on the $\mathrm{NO}_{2}$-sensing properties of both the sensors. The resistances of both the sensors in wet air $(80 \% \mathrm{RH})$ decreased with an increase in UV-light intensity, as is the case with those in dry air. The resistance of the $\mathrm{SnO}_{2}$ sensor in wet air $(80 \% \mathrm{RH})$ under no UV-light intensity (ca. $2.2 \times 10^{5} \Omega$ ) was slightly smaller than that in dry air (ca. $2.5 \times 10^{5} \Omega$, see Figs. 2 and 3), and the addition of moisture did not have a considerable influence on the resistance in air, even under UV-light irradiation. These results imply that adsorbed water molecules have only a little influence on the adsorption state of oxygen adsorbates $\left(\mathrm{O}_{2}^{-}\right)$on the $\mathrm{SnO}_{2}$ surface. The loading of $0.05 \mathrm{wt} \% \mathrm{Pd}$ largely increased the resistance of the $\mathrm{SnO}_{2}$ sensor, also in wet air $(80 \% \mathrm{RH})$ and the addition of moisture into air largely decreased the resistance of the $0.05 \mathrm{Pd} / \mathrm{SnO}_{2}$ sensor, with or without $\mathrm{UV}$ irradiation (e.g., ca. $6.3 \times 10^{5} \Omega$ in dry air (see Figs. 4 and 5) and ca. $2.8 \times 10^{5} \Omega$ in wet air $(80 \%$ RH) under no UV irradiation, and ca. $2.5 \times 10^{4} \Omega$ in dry air (see Figs. 4 and 5) and ca. $2.5 \times 10^{3} \Omega$ in wet air $(80 \% \mathrm{RH})$ under $\mathrm{UV}$ irradiation at $\left.75 \mathrm{~mW} \mathrm{~cm}^{-2}\right)$. These facts indicate that the loaded PdO nanoparticles enhanced the adsorption of water molecules on the $\mathrm{SnO}_{2}$ surface and then the adsorbed water molecules reduced the resistance of the $0.05 \mathrm{Pd} / \mathrm{SnO}_{2}$ sensor at $30^{\circ} \mathrm{C}[31]$. These

effects of the $\mathrm{Pd}$ loading on the resistance of $\mathrm{SnO}_{2}$ sensor at $30^{\circ} \mathrm{C}$ under UV-light irradiation seem to be different from those at elevated temperatures [47]. The injection of $\mathrm{NO}_{2}$ in wet air 
increased the resistance of both the sensors with or without UV-light irradiation, but the impacts of the moisture addition on the $\mathrm{NO}_{2}$-response behavior were dependent on the relative humidity and the UV-light intensity. The $\mathrm{NO}_{2}$ response of the $\mathrm{SnO}_{2}$ sensor drastically decreased with an increase in the relative humidity under no UV-light irradiation, and the $\mathrm{SnO}_{2}$ sensor showed only a small $\mathrm{NO}_{2}$ response $\left(R_{\mathrm{NO}_{2}} / R_{\mathrm{a}}\right.$ at $80 \% \mathrm{RH}$ : ca. 1.4$)$ in air containing a large amount of moisture under no UV-light irradiation. The UV-light irradiation enhanced the $\mathrm{NO}_{2}$ response of the $\mathrm{SnO}_{2}$ sensor in wet air, and the $\mathrm{NO}_{2}$ response of the $\mathrm{SnO}_{2}$ sensor in wet air under UV-light irradiation tended to increase with a decrease in UV-light intensity. However, the $\mathrm{NO}_{2}$ responses of the $\mathrm{SnO}_{2}$ sensor in wet air $(\geq 40 \% \mathrm{RH})$ even under weak UV-light irradiation (7 and $35 \mathrm{~mW}$ $\mathrm{cm}^{-2}$ ) were much smaller than those in dry air (see Figs. 2 and 3). On the other hand, the further increase in UV-light intensity (namely, at 75 and $134 \mathrm{~mW} \mathrm{~cm}^{-2}$ ) seems to decrease the dependency of relative humidity on the $\mathrm{NO}_{2}$ response of the $\mathrm{SnO}_{2}$ sensor, probably because the UV-light irradiation reduced the adsorption of water molecules on the $\mathrm{SnO}_{2}$ surface. The addition of moisture in air also led to slow down the response speed under UV-light irradiation (especially at $7 \mathrm{~mW} \mathrm{~cm} \mathrm{c}^{-2}, T_{\mathrm{RES}}(90)$ : ca. $27.5 \mathrm{~min}$ in wet air $(80 \% \mathrm{RH})$ in comparison with ca. 4.6 min in dry air (see Figs. 2 and 3)). These $\mathrm{NO}_{2}$-sensing properties of the $\mathrm{SnO}_{2}$ sensor show that a large amount of physisorbed water molecules, which do not contribute to a reduction in the sensor resistance, exist on the $\mathrm{SnO}_{2}$ surface in wet air with or without UV-light irradiation and they interfered the negatively charged adsorption of $\mathrm{NO}_{2}$ onto the $\mathrm{SnO}_{2}$ surface. However, the injection of a large amount of photon energy to the $\mathrm{SnO}_{2}$ sensor (i.e., strong UV-light irradiation at 75 and $134 \mathrm{~mW} \mathrm{~cm}^{-2}$ ) is likely to promote the desorption of the physisorbed water molecules on the $\mathrm{SnO}_{2}$ surface in wet air, to reduce the $\mathrm{RH}$ dependence of the $\mathrm{NO}_{2}$ response.

On the other hand, the injection of $\mathrm{NO}_{2}$ unstabilized the resistance of the $0.05 \mathrm{Pd} / \mathrm{SnO}_{2}$ sensor in wet air $(80 \% \mathrm{RH})$ under no UV-light irradiation even though the resistance in wet air $(80 \% \mathrm{RH})$ was able to be somehow measured $\left(R_{\mathrm{a}}\right.$ at $80 \% \mathrm{RH}$ : ca. $\left.2.5 \times 10^{5} \Omega\right)$, and thus the 
response transient of the $0.05 \mathrm{Pd} / \mathrm{SnO}_{2}$ sensor in wet air $(80 \% \mathrm{RH})$ under no UV-light irradiation is not shown in Figs. $\mathrm{S} 7$ and 11 . The $\mathrm{NO}_{2}$ response of the $0.05 \mathrm{Pd} / \mathrm{SnO}_{2}$ sensor was much larger than that of the $\mathrm{SnO}_{2}$ sensor, also in wet air under each UV-light irradiation intensity, and the $\mathrm{NO}_{2}$ response also tended to decrease with an increase in the relative humidity and UV-light intensity. In addition, the $\mathrm{NO}_{2}$ response at stronger UV-light irradiation $\left(\geq 35 \mathrm{~mW} \mathrm{~cm}^{-2}\right)$ was largely dependent on the relative humidity (especially in the range of $0-40 \% \mathrm{RH}$ (a small amount of relative humidity)). The stronger UV-light irradiation probably promoted the production of hydroxyl groups from physisorbed water molecules on the $0.05 \mathrm{Pd} / \mathrm{SnO}_{2}$ surface, to inhibit the adsorption of $\mathrm{NO}_{2}$. On the other hand, the $\mathrm{NO}_{2}$ response under the weakest UVlight irradiation (namely, at $7 \mathrm{~mW} \mathrm{~cm}^{-2}$ ) was the largest among all conditions, and it showed the smallest dependency of the $\mathrm{NO}_{2}$ response of the $0.05 \mathrm{Pd} / \mathrm{SnO}_{2}$ sensor on the relative humidity $\left.\left(R_{\mathrm{NO}_{2}} / R_{\mathrm{a}} \text { : ca. } 1.9 \times 10^{3} \text { in wet air }(80 \% \mathrm{RH}) \text { at } 7 \mathrm{~mW} \mathrm{~cm}\right)^{-2}\right)$. These results probably indicate that a small amount of photon energy (i.e., $\leq 7 \mathrm{~mW} \mathrm{~cm}{ }^{-2}$ ) promotes the desorption of physisorbed water molecules and then the effective adsorption of $\mathrm{NO}_{2}$ on the $0.05 \mathrm{Pd} / \mathrm{SnO}_{2}$ surface. The response speed of the $0.05 \mathrm{Pd} / \mathrm{SnO}_{2}$ sensor in wet air $(80 \% \mathrm{RH})$ was quite slower than that in dry air. In addition, the $0.05 \mathrm{Pd} / \mathrm{SnO}_{2}$ sensor showed the fastest response speed in

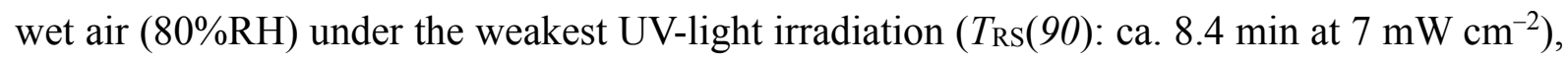
and the response speed tended to slow down with an increase in UV-light intensity in spite of the small $\mathrm{NO}_{2}$ response (e.g., $T_{\mathrm{RS}}(90)$ : ca. $11.8 \mathrm{~min}$ at $134 \mathrm{~mW} \mathrm{~cm}^{-2}$ ). On the other hand, the recovery speed of the $0.05 \mathrm{Pd} / \mathrm{SnO}_{2}$ sensor was hardly dependent on relative humidity (e.g., $T_{\mathrm{RC}}(60)$ in wet air $(80 \% \mathrm{RH})$ : ca. $18.9 \mathrm{~min}$ and $5.3 \mathrm{~min}$ at $7 \mathrm{~mW} \mathrm{~cm}^{-2}$ and $134 \mathrm{~mW} \mathrm{~cm}^{-2}$, respectively, and $T_{\mathrm{RC}}(60)$ in dry air (cf. Figs. 2 and 3): ca. $16.1 \mathrm{~min}$ and $5.5 \mathrm{~min}$ at $7 \mathrm{~mW} \mathrm{~cm}^{-2}$ and $134 \mathrm{~mW} \mathrm{~cm}^{-2}$, respectively), and the recovery speed in wet air also increased with an increase in UV-light intensity, as is the case in dry air. The behavior probably indicates that the desorption rate of $\mathrm{NO}_{2}^{-}$accelerated with an increase in UV-light intensity, but physisorbed 
water molecules and hydroxyl groups on the $0.05 \mathrm{Pd} / \mathrm{SnO}_{2}$ surface have little influence on the desorption rate of $\mathrm{NO}_{2}{ }^{-}$under UV-light irradiation. 


\section{Conclusion}

Effects of noble-metal loading onto typical semiconducting oxides $\left(\mathrm{SnO}_{2}, \mathrm{In}_{2} \mathrm{O}_{3}\right.$, and $\left.\mathrm{WO}_{3}\right)$, intensity of UV-light irradiation to these sensors and addition of moisture in target gas on the $\mathrm{NO}_{2}$-sensing properties of the oxides-based semiconductor gas sensors were investigated in air at $30^{\circ} \mathrm{C}$ in this study. The UV-light irradiation effectively reduced the resistances of all the pristine oxide sensors and accelerated the response and recovery speeds of the $\mathrm{SnO}_{2}$ and $\operatorname{In}_{2} \mathrm{O}_{3}$ sensors in dry air, while the magnitude of response of all the sensors to $5 \mathrm{ppm} \mathrm{NO}_{2}$ tended to decrease with an increase in UV-light intensity. However, only the $\mathrm{SnO}_{2}$ sensor showed larger $\mathrm{NO}_{2}$ response in dry air under weak UV-light irradiation $\left(\leq 35 \mathrm{~mW} \mathrm{~cm}^{-2}\right)$ than that under no UV-light irradiation. The Pd loading increased the sensor resistance and enhanced the $\mathrm{NO}_{2}$ response of the $\mathrm{SnO}_{2}$ sensor in dry air under every UV-light irradiation intensity. In addition, the Pd loading accelerated the response speeds of the $\mathrm{SnO}_{2}$ sensor mainly under weak UVlight irradiation $\left(\leq 35 \mathrm{~mW} \mathrm{~cm}^{-2}\right)$, while the recovery speeds of the $n \mathrm{Pd} / \mathrm{SnO}_{2}$ sensors were faster than that of the $\mathrm{SnO}_{2}$ sensors under every UV-light irradiation intensity. The difference in these $\mathrm{NO}_{2}$-sensing properties of $\mathrm{SnO}_{2}$ and $n \mathrm{Pd} / \mathrm{SnO}_{2}$ sensors in dry air with and without UV-light irradiation seems to arise from adsorption-desorption rates of $\mathrm{NO}_{2}$ and $\mathrm{O}_{2}$ on each oxide surface under each UV-light irradiation intensity. In addition, the Pd loading onto the $\mathrm{SnO}_{2}$ sensor was more effective in improving the $\mathrm{NO}_{2}$-sensing properties than the $\mathrm{Pt}$ loading onto the $\mathrm{SnO}_{2}$ sensor as well as the Pd loading onto the $\mathrm{In}_{2} \mathrm{O}_{3}$ sensor. On the other hand, the addition of moisture in target gas tended to reduce the magnitude of $\mathrm{NO}_{2}$ responses of both the $\mathrm{SnO}_{2}$ and $0.05 \mathrm{Pd} / \mathrm{SnO}_{2}$ sensors and slowed down their response speeds, but the $0.05 \mathrm{Pd} / \mathrm{SnO}_{2}$ sensor maintained relatively large $\mathrm{NO}_{2}$ response and fast response speed even in wet air, only under weak UV-light irradiation $\left(7 \mathrm{~mW} \mathrm{~cm}^{-2}\right)$. 


\section{References}

1. D. L. Jarvis, B. P. Leaderer, S. Chinn, P. G. Burney, Indoor nitrous acid and respiratory symptoms and lung function in adults, Thorax 60 (2005) 474-479.

2. A. J. Chauhan, S. L. Johnston, Air pollution and infection in respiratory illness, British Medical Bulletin 68 (2003) 95-112.

3. D. A. Burns, J. Aherne, D. A. Gay, C. M. B. Lehmann, Acid rain and its environmental effects: Recent scientific advances, Atmos. Environ. 146 (2016) 1-4.

4. Y. Kanaya, H. Tanimoto, J. Matsumoto, H. Furutani, S. Hashimoto, Y. Komazaki, S. Tanaka, Y. Yokouchi, S. Kato, Y. Kajii, H. Akimoto, Diurnal variations in $\mathrm{H}_{2} \mathrm{O}_{2}, \mathrm{O}_{3}, \mathrm{PAN}, \mathrm{HNO}_{3}$ and aldehyde concentrations and $\mathrm{NO} / \mathrm{NO}_{2}$ ratios at Rishiri Island, Japan: Potential influence from iodine chemistry, Sci. Total Environ. 376 (2007) 185-197.

5. A. Notario, I. Bravo, J. A. Adame, Y. Díaz-de-Mera, A. Aranda, A. Rodríguez, D. Rodríguez, Analysis of $\mathrm{NO}, \mathrm{NO}_{2}, \mathrm{NOx}, \mathrm{O}_{3}$ and oxidant $\left(\mathrm{O}_{\mathrm{x}}=\mathrm{O}_{3}+\mathrm{NO}_{2}\right)$ levels measured in a metropolitan area in the southwest of Iberian Peninsula, Atmos. Res. 104-105 (2012) $217-226$.

6. M. Ono, K. Shimanoe, N. Miura, N. Yamazoe, Solid-state amperometric sensor based on a sodium ion conductor for detection of total NOx in an atmospheric environment, Electrochem. Solid State Lett. 2 (1999) 349-351.

7. J. W. Yoon, M. L. Grilli, E. Di Bartolomeo, R. Polini, E. Traversa, The $\mathrm{NO}_{2}$ response of solid electrolyte sensors made using nano-sized $\mathrm{LaFeO}_{3}$ electrode, Sens. Actuators $\mathrm{B} 76$ (2001) 483-488.

8. T. Ueda, M. Sakai, K. Kamada, T. Hyodo, Y. Shimizu, Effects of composition and structure of sensing electrode on $\mathrm{NO}_{2}$ sensing properties of mixed potential-type YSZ-based gas sensors, Sens. Actuators B 237 (2016) 247-255.

9. T. Nezel, A. Fakler, G. Zhylyak, G. J. Mohr, U. E. Spichiger-Keller, A highly sensitive $\mathrm{NO}_{2}-$ 
selective optode membrane, Sens. Actuators B 70 (2000) 165-169.

10. A. Paliwal, A. Sharma, M. Tomar, V. Gupta, Room temperature detection of $\mathrm{NO}_{2}$ gas using optical sensor based on surface plasmon resonance technique, Sens. Actuators B 216 (2015) 497-503.

11. M. Penza, L. Vasanelli, SAW NOx gas sensor using $\mathrm{WO}_{3}$ thin-film sensitive coating, Sens. Actuators B 41 (1997) 31-36.

12. H. Seh, T. Hyodo, H. L. Tuller, Bulk acoustic wave resonator as a sensing platform for NOx at high temperatures, Sens. Actuators B 108 (2005) 547-552.

13. G. Sberveglieri, G. Faglia, S. Groppelli, P. Nelli, Methods for the preparation of NO, $\mathrm{NO}_{2}$ and $\mathrm{H}_{2}$ sensors based on tin oxide thin films, grown by means of the r.f. magnetron sputtering technique, Sens. Actuators B 8 (1995) 388-391.

14. T. Hyodo, K. Sasahara, Y. Shimizu, M. Egashira, Preparation of macroporous $\mathrm{SnO}_{2}$ films using PMMA microspheres and their sensing properties to $\mathrm{NOx}$ and $\mathrm{H}_{2}$, Sens. Actuators B 106 (2005) 580-590.

15. A. A. Firooz, T. Hyodo, A. Reza Mahjoub, A. Ali Khodadadi, Y. Shimizu, Synthesis and Gas-sensing Properties of Nano- and Meso-porous $\mathrm{MoO}_{3}$-doped $\mathrm{SnO}_{2}$, Sens. Actuators $\mathrm{B}$ 147 (2010) 554-560.

16. H.-Y. Li, Z.-X. Cai, J.-C. Ding, Z. Guo, Gigantically enhanced NO sensing properties of $\mathrm{WO}_{3} / \mathrm{SnO}_{2}$ double layer sensors with Pd decoration, Sens. Actuators B 220 (2015) 398405.

17. A. Gurlo, M. Ivanovskaya, N. Bârsan, M. Schweizer-Berberich, U. Weimar, W. Göpel, A. Diéques, Grain size control in nanocrystalline $\mathrm{In}_{2} \mathrm{O}_{3}$ semiconductor gas sensors, Sens. Actuators B 44 (1997) 327-333.

18. T. Hyodo, H. Inoue, H. Motomura, K. Matsuo, T. Hashishin, J. Tamaki, Y. Shimizu, M. Egashira, $\mathrm{NO}_{2}$ sensing properties of macroporous $\mathrm{In}_{2} \mathrm{O}_{3}$-based powders fabricated by 
utilizing ultrasonic spray pyrolysis employing polymethylmethacrylate microspheres as a template, Sens. Actuators B 151 (2010) 265-273.

19. P. Sowti Khiabani, A. Hosseinmardi, E. Marzbanrad, S. Ghashghaie, C. Zamani, M. Keyanpour-Rad, B. Raissi, $\mathrm{NO}_{2}$ gas sensor fabrication through AC electrophoretic deposition from electrospun $\mathrm{In}_{2} \mathrm{O}_{3}$ nanoribbons, Sens. Actuators B 162 (2012) 102-107.

20. M. Akiyama, J. Tamaki, N. Miura, N. Yamazoe, Tungsten oxide-based semiconductor sensor highly sensitive to NO and NO 2 , Chem. Lett. 1991 (1991) 1611-1614.

21. T. Hyodo, Y. Tominaga, T. Yamaguchi, A. Kawahara, H. Katsuki, Y. Shimizu, M. Egashira, NOx sensing properties of $\mathrm{WO}_{3}$-based semiconductor gas sensors fabricated by slide-off transfer printing, Electrochemistry 71 (2003) 481-484.

22. J. Tamaki, T. Hashishin, Y. Uno, D. Viet Dao, S. Sugiyama, Ultrahigh-sensitive $\mathrm{WO}_{3}$ nanosensor with interdigitated Au nano-electrode for $\mathrm{NO}_{2}$ detection, Sens. Actuators $\mathrm{B} 132$ (2008) 234-238.

23. T. Kida, A. Nishiyama, M. Yuasa, K. Shimanoe, N. Yamazoe, Highly sensitive $\mathrm{NO}_{2}$ sensors using lamellar-structured $\mathrm{WO}_{3}$ particles prepared by an acidification method, Sens. Actuators B 135 (2009) 568-574.

24. E. Comini, G. Faglia, G. Sberveglieri, UV light activation of tin oxide thin films for $\mathrm{NO}_{2}$ sensing at low temperatures, Sens. Actuators B 78 (2001) 73-77.

25. K. Anothainart, M. Burgmair, A. Karthigeyan, M. Zimmer, I. Eisele, Light enhanced $\mathrm{NO}_{2}$ gas sensing with tin oxide at room temperature: conductance and work function measurements, Sens. Actuators B 93 (2003) 580-584.

26. J. D. Prades, R. Jimenez-Diaz, F. Hernandez-Ramirez, S. Barth, A. Cirera, A. RomanoRodriguez, S. Mathur, J.R. Morante, Equivalence between thermal and room temperature UV light-modulated responses of gas sensors based on individual $\mathrm{SnO}_{2}$ nanowires, Sens. Actuators B 140 (2009) 337-341. 
27. T. Wagner, C.-D. Kohl, C. Malagù, N. Donato, M. Latino, G. Neri, M. Tiemann, UV lightenhanced $\mathrm{NO}_{2}$ sensing by mesoporous $\mathrm{In}_{2} \mathrm{O}_{3}$ : Interpretation of results by a new sensing model, Sens. Actuators B 187 (2013) 488-494.

28. A. Ilin, M. Martyshov, E. Forsh, P. Forsh, M. Rumyantseva, A. Abakumov, A. Gaskov, P. Kashkarov, UV effect on $\mathrm{NO}_{2}$ sensing properties of nanocrystalline $\mathrm{In}_{2} \mathrm{O}_{3}$, Sens. Actuators B 231 (2016) 491-496.

29. L. Ding, X. Ding, D. Zeng, S. Tian, H. Li, C. Xie, Visible-light activate mesoporous $\mathrm{WO}_{3}$ sensors with enhanced formaldehyde-sensing property at room temperature, Sens. Actuators B 163 (2012) 260-266.

30. K. Urata, T. Ueda, T. Hyodo, Y. Shimizu, Gas-sensing properties of semiconductor gas sensors operated with UV-light irradiation, Chem. Sens., 30(A) (2014) 109-111.

31. T. Hyodo, K. Urata, T. Ueda, K. Kamada, Y. Shimizu, $\mathrm{NO}_{2}$-sensing properties of $\mathrm{SnO}_{2}$ based sensors operated with UV-light irradiation, Chem. Sens., 31(A) (2015) 13-15.

32. F. H. Saboor, T. Ueda, K. Kamada, T. Hyodo, Y. Mortazavi, A. Ali Khodadadi, Y. Shimizu, Enhanced $\mathrm{NO}_{2}$ gas sensing performance of bare and Pd-loaded $\mathrm{SnO}_{2}$ thick film sensors under UV-light irradiation at room temperature, Sens. Actuators B 223 (2016) 429-439.

33. N. Barsan, U. Weimar, Conduction model of metal oxide gas sensors, J. Electroceram. 7 (2002) 143-167.

34. S. Matsushima, T. Maekawa, J. Tamaki, N. Miura, N. Yamazoe, Dispersion and electric interaction of palladium particles supported on tin oxide, Nippon Kagaku Kaishi 1991 (1991) 1677-1683.

35. T. Skála, K. Veltruská, M. Moroseac, I. Matolínová, A. Cirera, V. Matolín, Redox process of Pd-SnO 2 system, Surf. Sci. 566-568 (2004) 1217-1221.

36. T. Hyodo, T. Yamashita, Y. Shimizu, Effects of surface modification of noble-metal sensing electrodes with $\mathrm{Au}$ on the hydrogen-sensing properties of diode-type gas sensors 
employing an anodized titania film, Sens. Actuators B 207 (2015) 105-116.

37. M. A. Bulter, D. S. Ginley, Prediction of flatband potentials at semiconductor-electrolyte interfaces form atomic electronegativities, J. Electrochem. Soc., 125 (1978) 228-232.

38. M. N. Islam, M. O. Hakim, Electron affinity and work function of polycrystalline $\mathrm{SnO}_{2}$ thin film, J. Mater. Sci. Lett. 5 (1986) 63-65.

39. J. Tauc, R. Grigorovici, A. Vancu, Optical properties and electronic structure of amorphous germanium, Phys. Status Solidi 15 (1966) 627-637.

40. M. Batzill, U. Diebold, The surface and materials science of tin oxide, Prog. Surf. Sci. 79 (2005) 47-154.

41. O. Mounkachi, E. Salmani, H. El Moussaoui, R. Masrour, M. Hamedoun, H. Ez-Zahraouy, E. K. Hlil, A. Benyousse, High blocking temperature in $\mathrm{SnO}_{2}$ based super-paramagnetic diluted magnetic semiconductor, J. Alloy. Compd. 614 (2014) 401-407.

42. Y. Li, W. Yin, R. Deng, R. Chen, J. Chen, Q. Yan, B. Yao, H. Sun, S.-H. Wei, T/ Wu, Realizing a $\mathrm{SnO}_{2}$-based ultraviolet light-emitting diode via breaking the dipole-forbidden rule, NPG Asia Mater. 4 (2012) e30.

43. B. Ruhland, T. Becker, G. Müller, Gas-kinetic interactions of nitrous oxides with $\mathrm{SnO}_{2}$ surfaces, Sens. Actuators B 50 (1998) 85-94.

44. E. P. Gardner, P. D. Sperry, J. G. Calvert, Primary quantum yields of $\mathrm{NO}_{2}$ photodissociation, J. Geophys. Res. 92 (1987) 6642-6652.

45. O. Lang, C. Pettenkofer, J. F. Sanchez-Royo, A. Segura, A. Klein, W. Jaegermann, Thin film growth and band lineup of $\operatorname{In}_{2} \mathrm{O}_{3}$ on the layered semiconductor InSe, J. Appl. Phys. 86 (1999) 5687-5691.

46. A. V. Kalinkin, A. M. Sorokin, M. Y. Smirnov, V. I. Bukhtiyarov, Size effect on the oxidation of platinum nanoparticles on graphite with nitrogen dioxide: an XPS and STM study, Kinet. Catal. 55 (2014) 354-360. 
47. N. Ma, K. Suematsu, M. Yuasa, T. Kida, K. Shimanoe, Effect of water vapor on Pd-loaded $\mathrm{SnO}_{2}$ nanoparticles gas sensor, ACS Appl. Mater. Inter. 7 (2015) 5863-5869. 


\section{Figure Captions}

Fig. 1. Schematic drawing of $0.05 \mathrm{Pd} / \mathrm{SnO}_{2}$ sensor and experimental setup for gas-sensing measurements.

Fig. 2. Response transients of $\mathrm{SnO}_{2}$ sensor to $5 \mathrm{ppm} \mathrm{NO}_{2}$ at $30^{\circ} \mathrm{C}$ in dry air under different UV-light irradiation intensities.

Fig. 3. Variations in (a) responses to $5 \mathrm{ppm} \mathrm{NO}_{2}\left(R_{\mathrm{NO}_{2}} / R_{\mathrm{a}}\right)$, (b) resistances in dry air $\left(R_{\mathrm{a}}\right)$, and (c) $90 \%$ response $\left(T_{\mathrm{RS}}(90)\right.$, open symbols) and $10 \%$ recovery times $\left(T_{\mathrm{RC}}(10)\right.$, filled symbols) of $\mathrm{SnO}_{2}$ sensor with UV-light intensity, together with those of $\operatorname{In}_{2} \mathrm{O}_{3}$, and $\mathrm{WO}_{3}$ sensors.

Fig. 4. Response transients of $0.05 \mathrm{Pd} / \mathrm{SnO}_{2}$ and $0.07 \mathrm{Pd} / \mathrm{SnO}_{2}$ sensors to $5 \mathrm{ppm} \mathrm{NO}_{2}$ at $30^{\circ} \mathrm{C}$ in dry air under different UV-light irradiation intensities.

Fig. 5. Variations in response to $5 \mathrm{ppm} \mathrm{NO} 2\left(R_{\mathrm{NO}_{2}} / R_{\mathrm{a}}\right)$ and resistance of all $n \mathrm{Pd} / \mathrm{SnO}_{2}$ sensors in dry air $\left(R_{\mathrm{a}}\right)$ with the amount of Pd loaded, together with those of $\mathrm{SnO}_{2}$ sensor.

Fig. 6. XPS spectra of $\mathrm{Pd}$ on the surface of $0.05 \mathrm{Pd} / \mathrm{SnO}_{2}$ and $0.10 \mathrm{Pd} / \mathrm{SnO}_{2}$ powders after heat treatment at $500^{\circ} \mathrm{C}$ for $1 \mathrm{~h}$ in ambient air.

Fig. 7. (a) Representative response transients of $\mathrm{SnO}_{2}$ and $0.05 \mathrm{Pd} / \mathrm{SnO}_{2}$ sensors to $30 \% \mathrm{O}_{2}$ at $30^{\circ} \mathrm{C}$ in dry $\mathrm{N}_{2}$ and (b) variations in response of these sensors to $30 \% \mathrm{O}_{2}$ at $30^{\circ} \mathrm{C}$ in dry $\mathrm{N}_{2}$ with UV-light intensity.

Fig. 8. Diffuse reflectance UV-Vis spectra of (a) $\mathrm{SnO}_{2}$ and (b) $0.05 \mathrm{Pd} / \mathrm{SnO}_{2}$ powders, together with their Tarc plots.

Fig. 9. XPS spectra of Pt on the surface of $0.05 \mathrm{Pt} / \mathrm{SnO}_{2}$ and $0.10 \mathrm{Pt} / \mathrm{SnO}_{2}$ powder after heat treatment at $500^{\circ} \mathrm{C}$ for $1 \mathrm{~h}$ in ambient air.

Fig. 10. Variations in response of $0.05 \mathrm{Pt} / \mathrm{SnO}_{2}$ and $0.10 \mathrm{Pt} / \mathrm{SnO}_{2}$ sensors to $5 \mathrm{ppm} \mathrm{NO}_{2}$ $\left(R \mathrm{NO}_{2} / R \mathrm{a}\right)$ with UV-light intensity, together with those of $\mathrm{SnO}_{2}, 0.05 \mathrm{Pd} / \mathrm{SnO}_{2}$ and $0.10 \mathrm{Pd} / \mathrm{SnO}_{2}$ sensors. 
Fig. 11. Variations in response of $\mathrm{SnO}_{2}$ and $0.05 \mathrm{Pd} / \mathrm{SnO}_{2}$ sensors to $5 \mathrm{ppm} \mathrm{NO}_{2}\left(R_{\mathrm{NO}_{2}} / R_{\mathrm{a}}\right)$ at $30^{\circ} \mathrm{C}$ in air under UV-light irradiation intensities with relative humidity. 
(b) Experimental setup
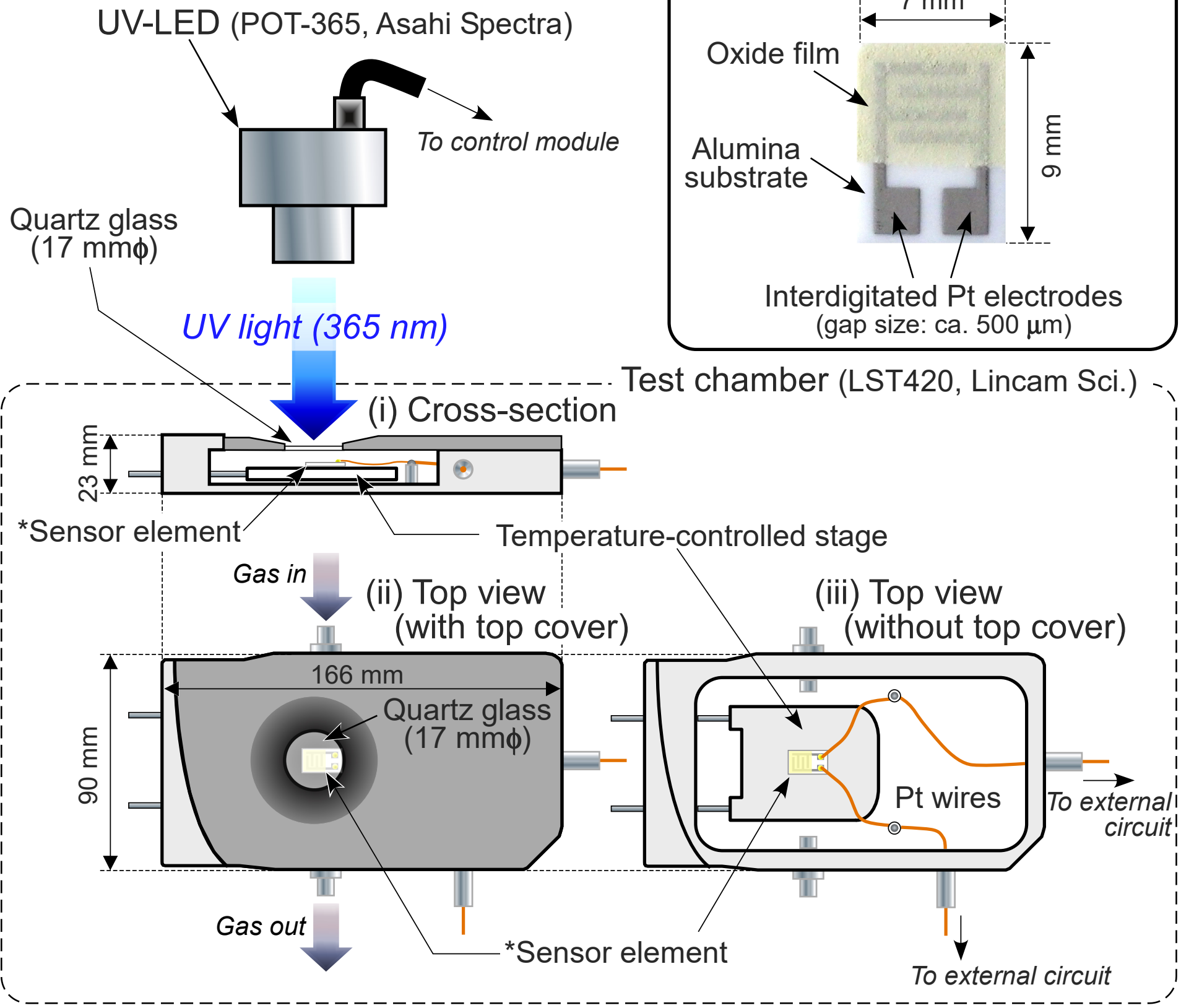

Fig. 1. Hyodo et al. (a) Sensor element*

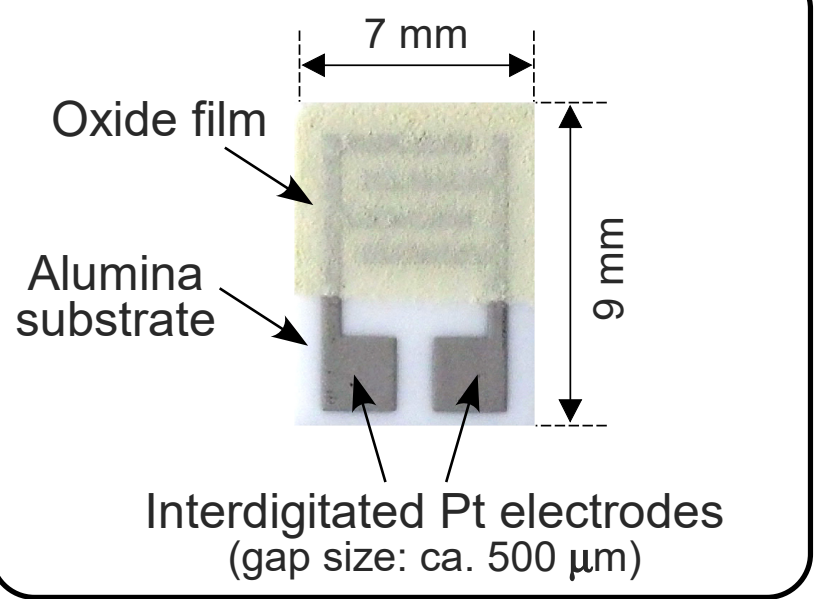

Interdigitated Pt electrodes (gap size: ca. $500 \mu \mathrm{m}$ ) 


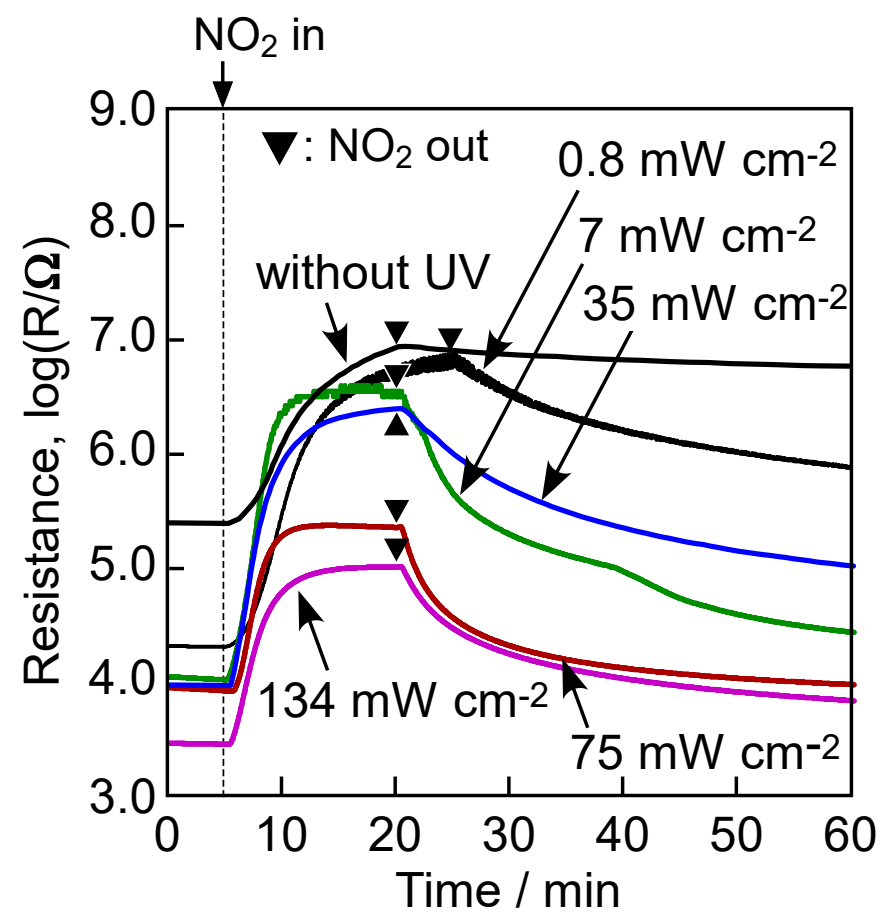

Fig. 2. Hyodo et al. 


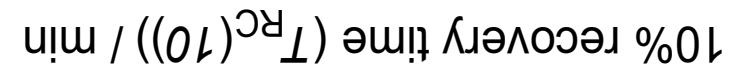

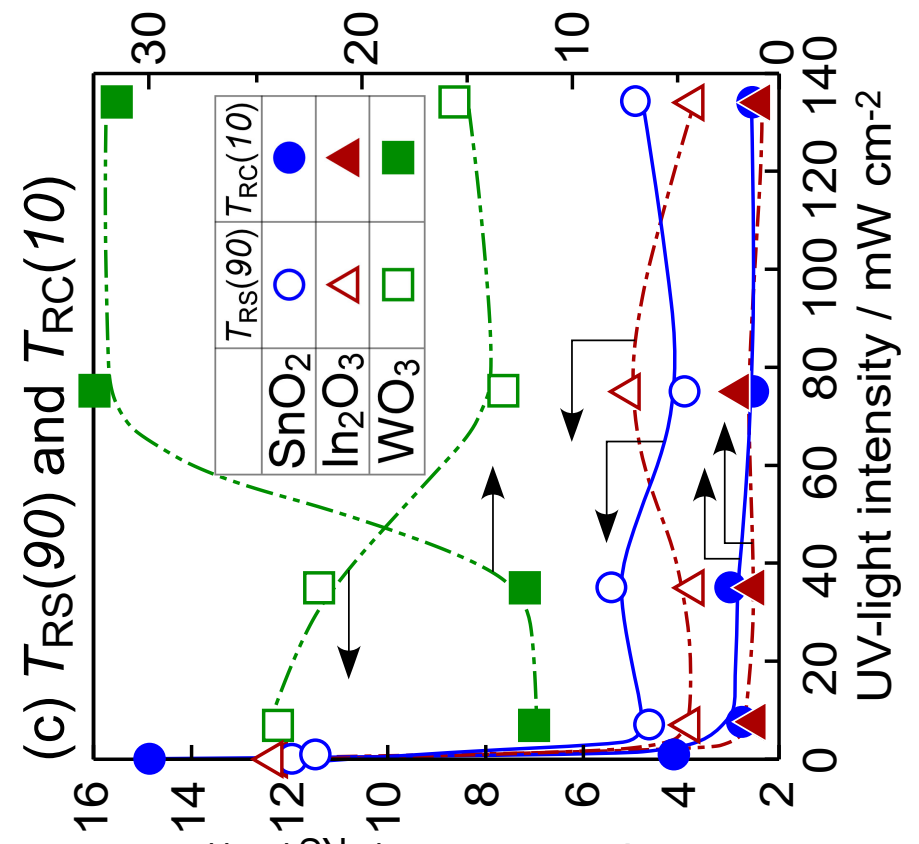

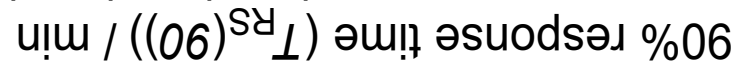
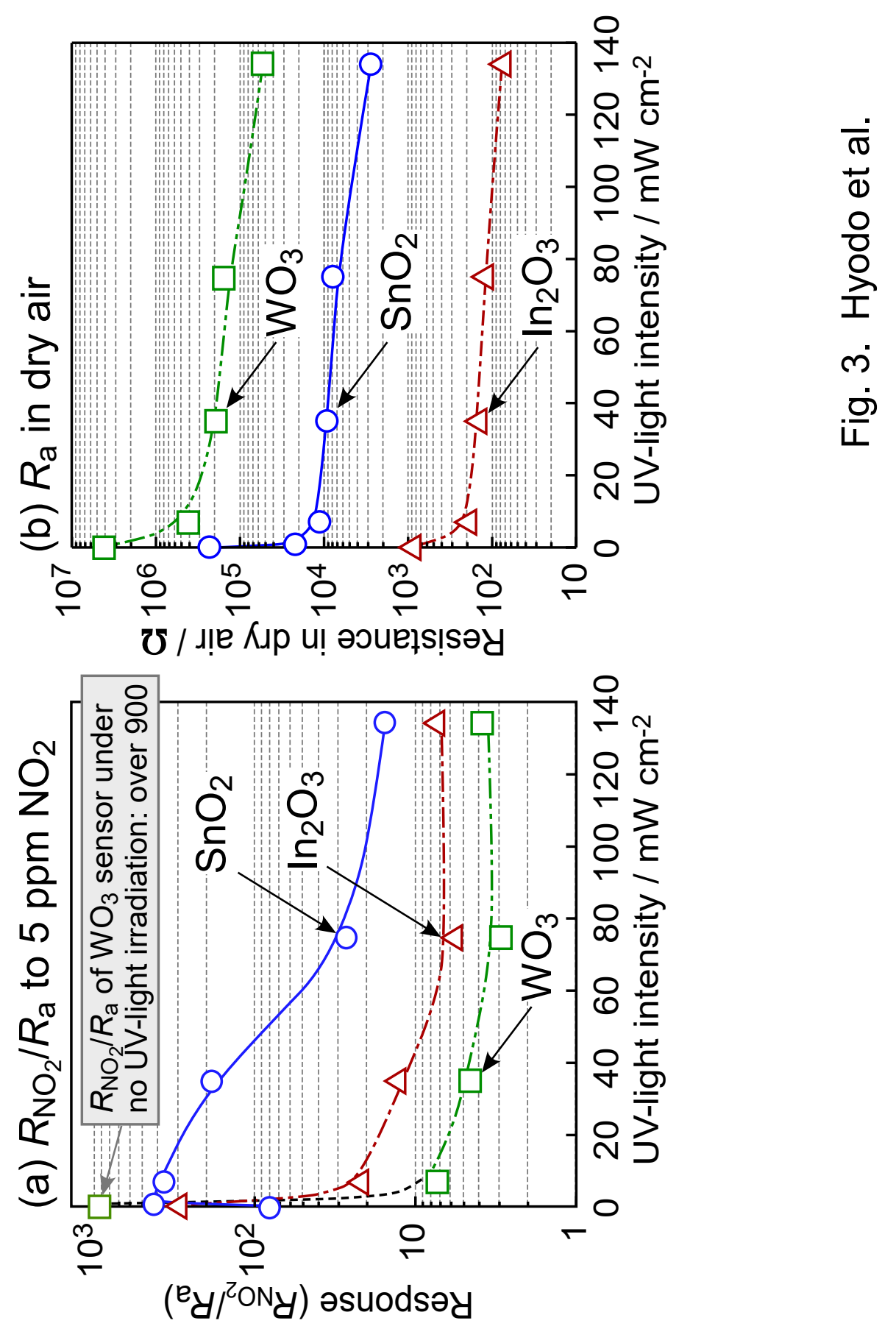


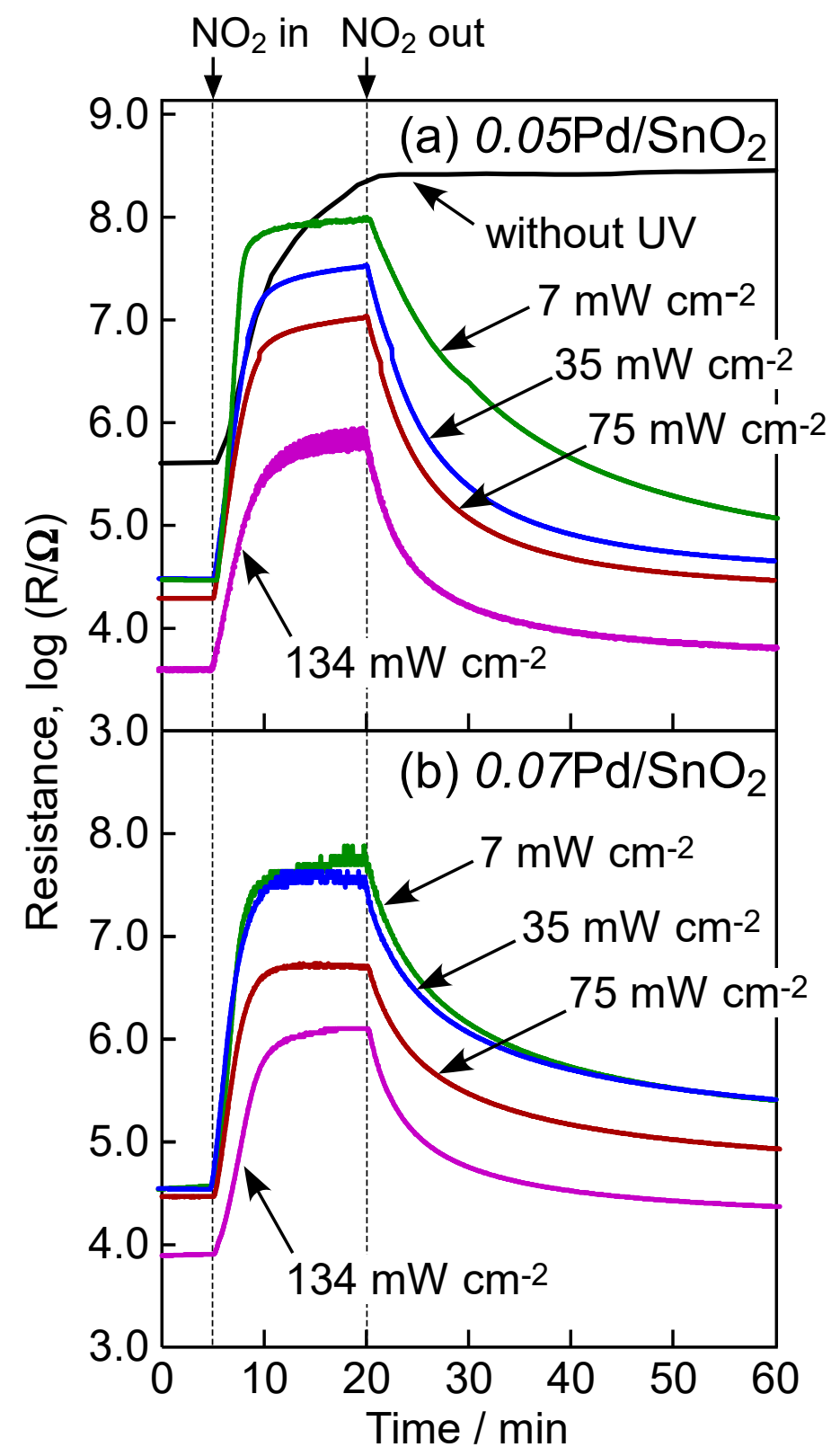

Fig. 4. Hyodo et al. 

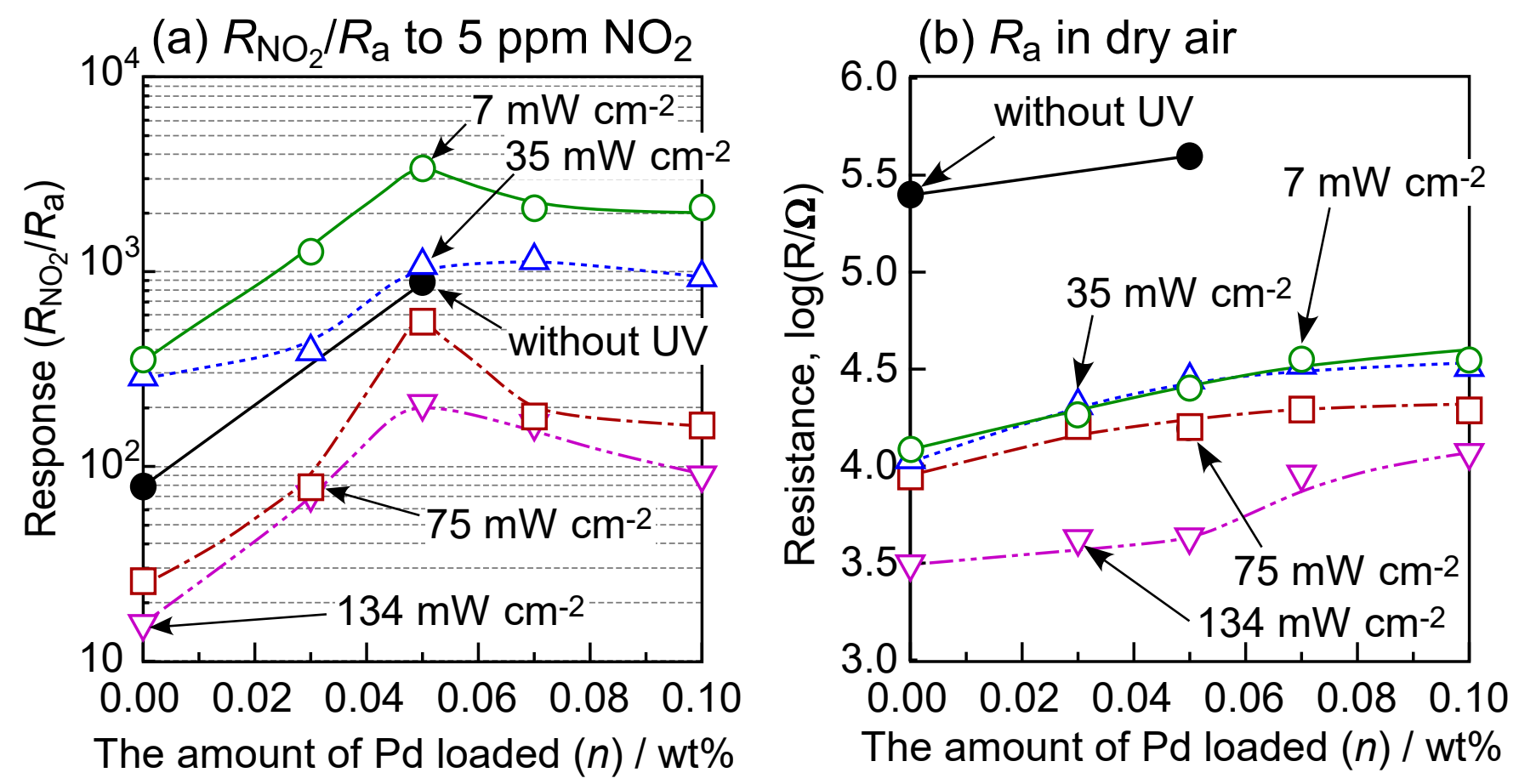

Fig. 5. Hyodo et al. 


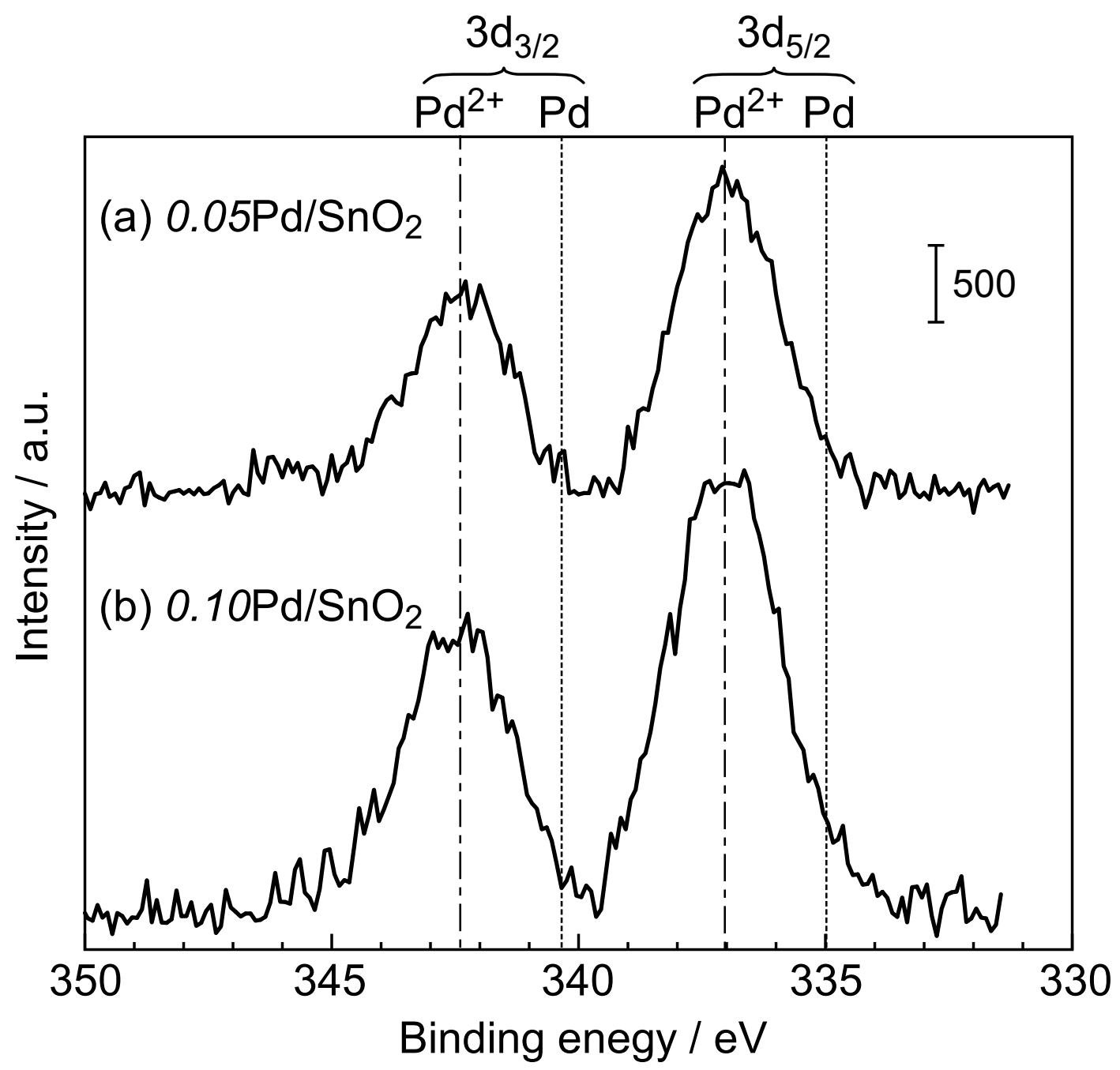

Fig. 6. Hyodo et al. 
(a) Response transients

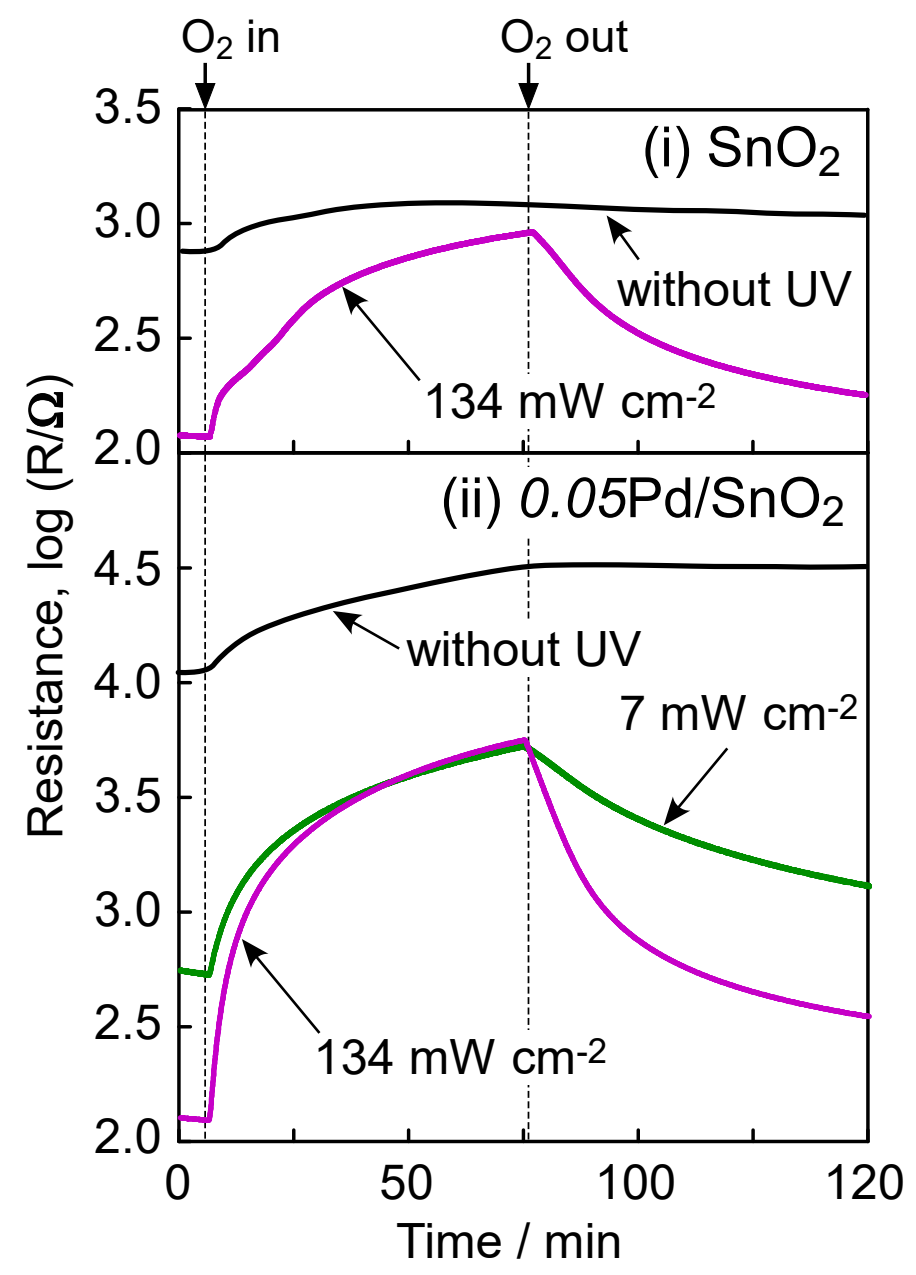

(b) Response to $30 \% \mathrm{O}_{2}$ in $\mathrm{N}_{2}$

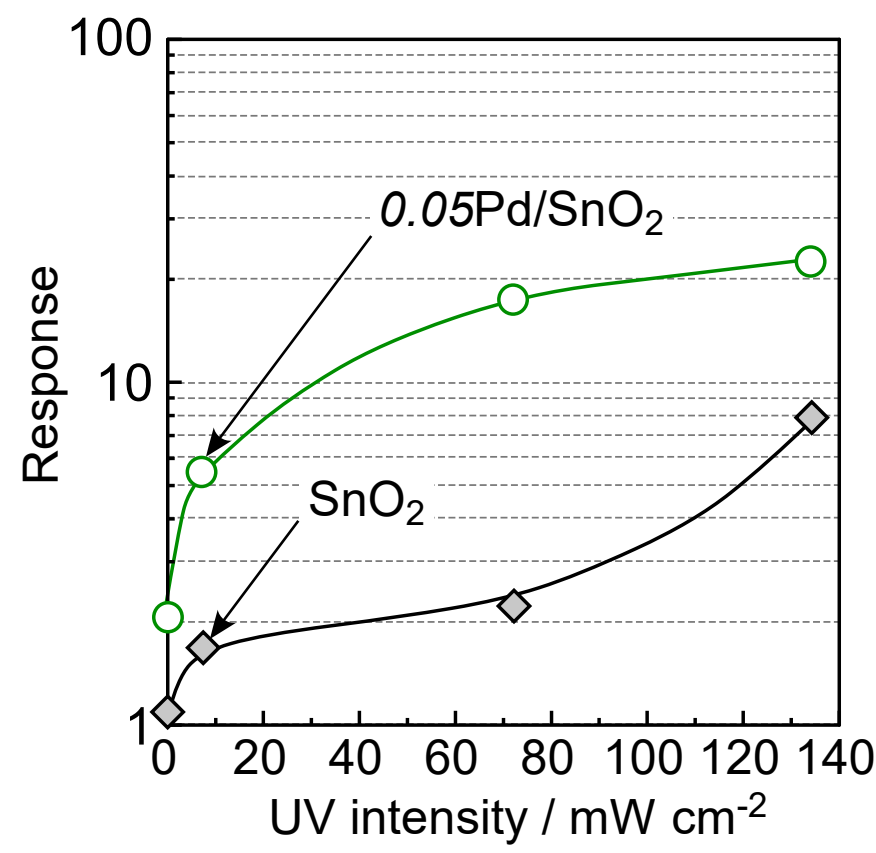

Fig. 7. Hyodo et al. 


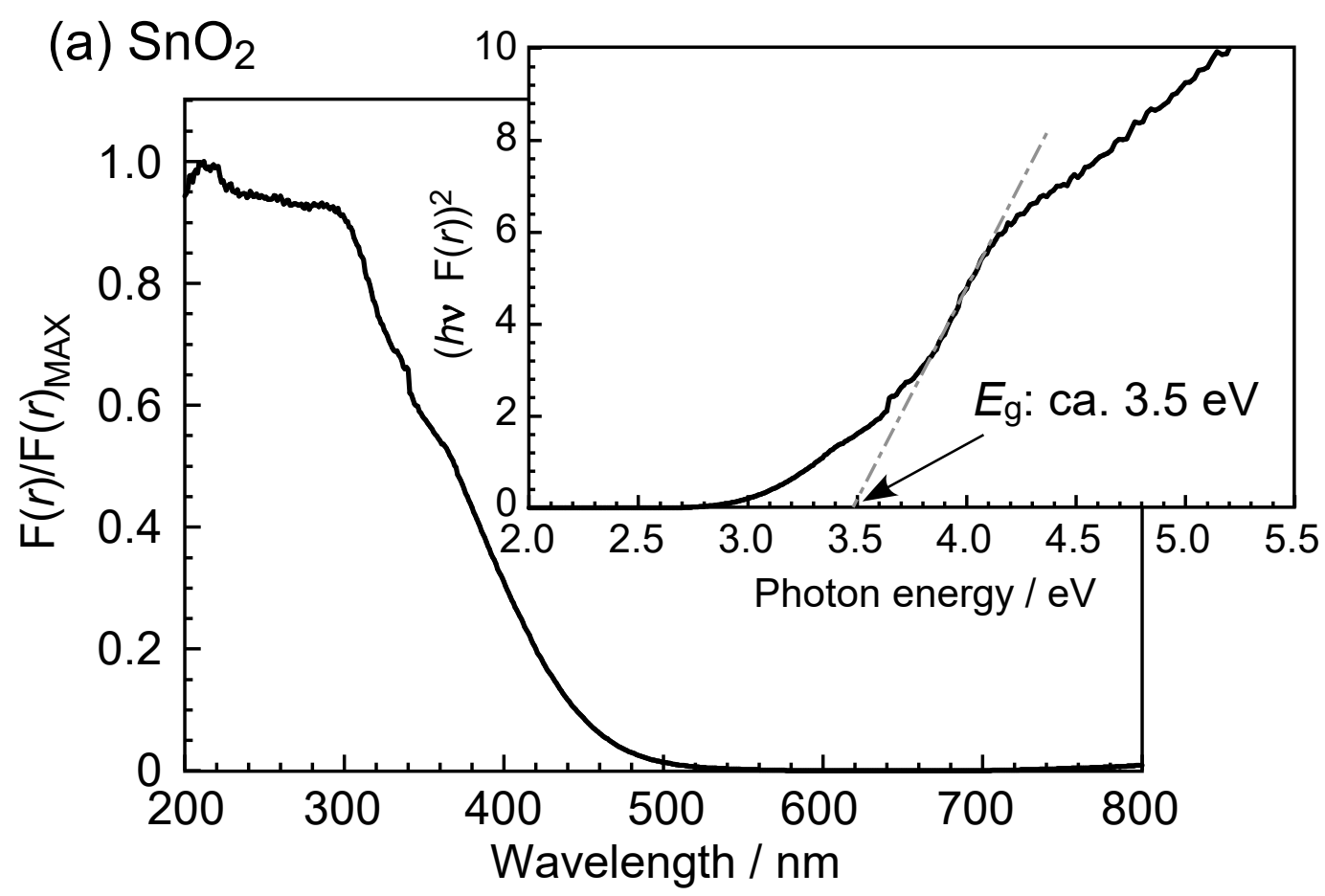

(b) $0.05 \mathrm{Pd} / \mathrm{SnO}_{2}$

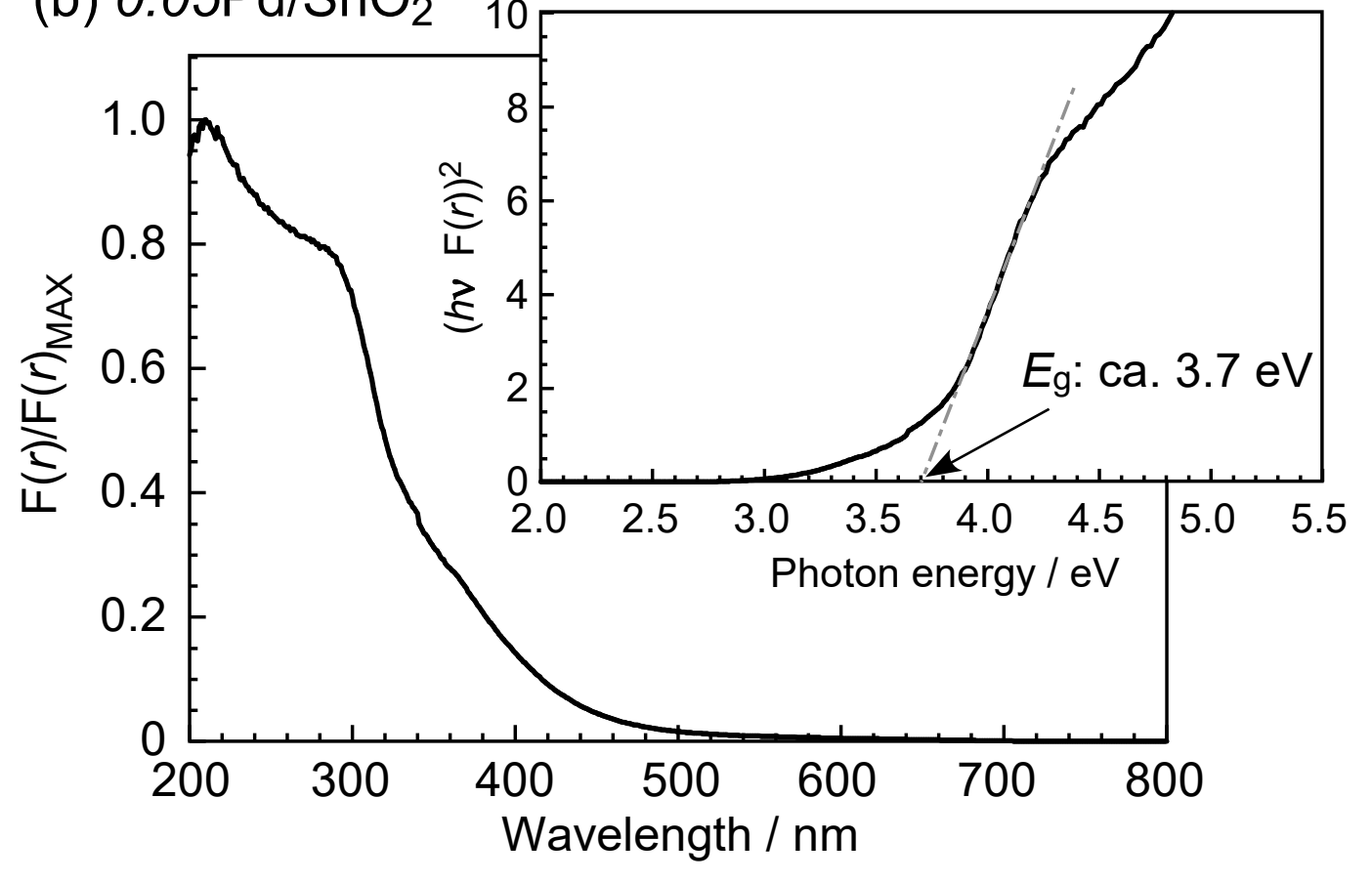

Fig. 8. Hyodo et al. 


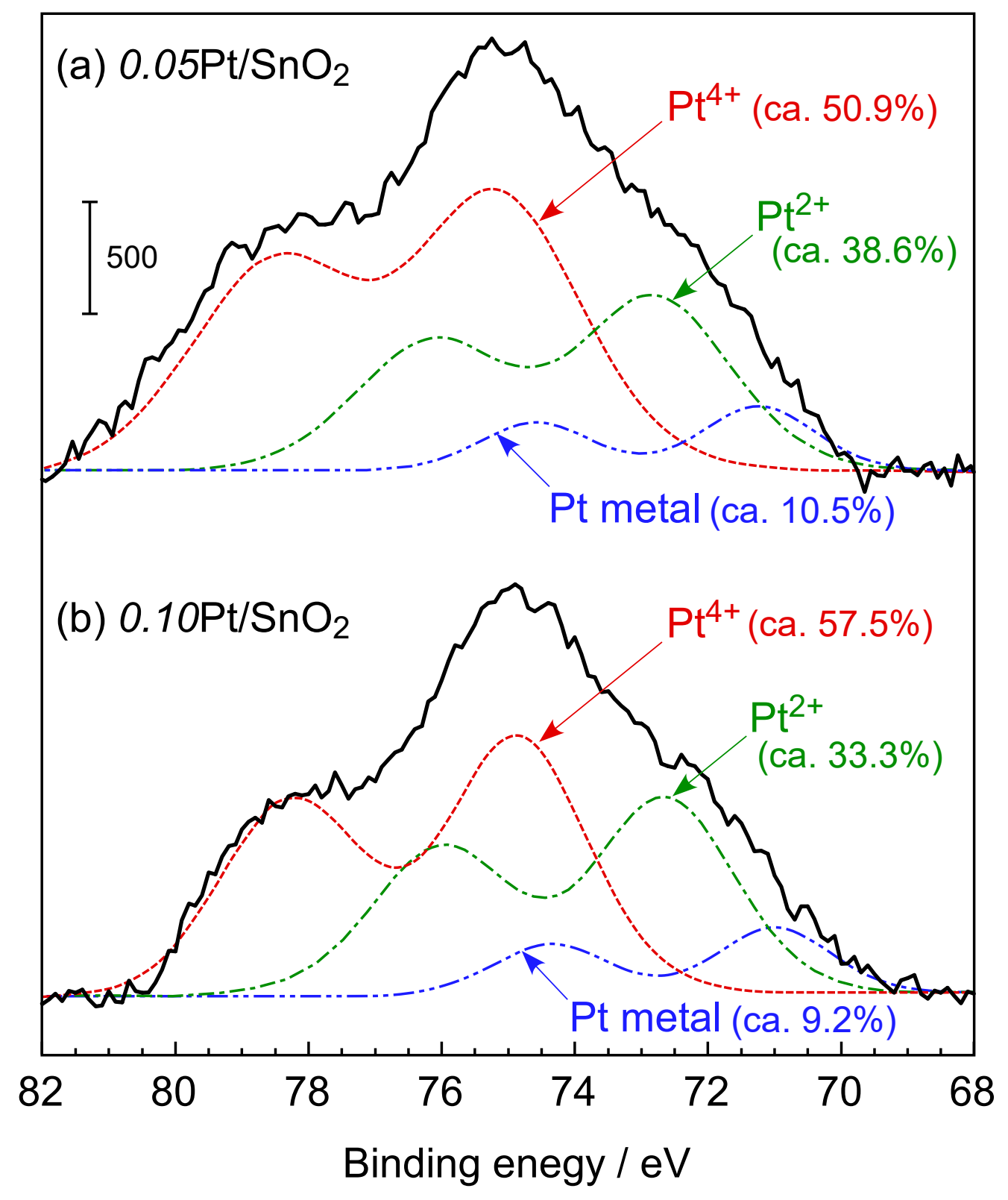

Fig. 9. Hyodo et al. 


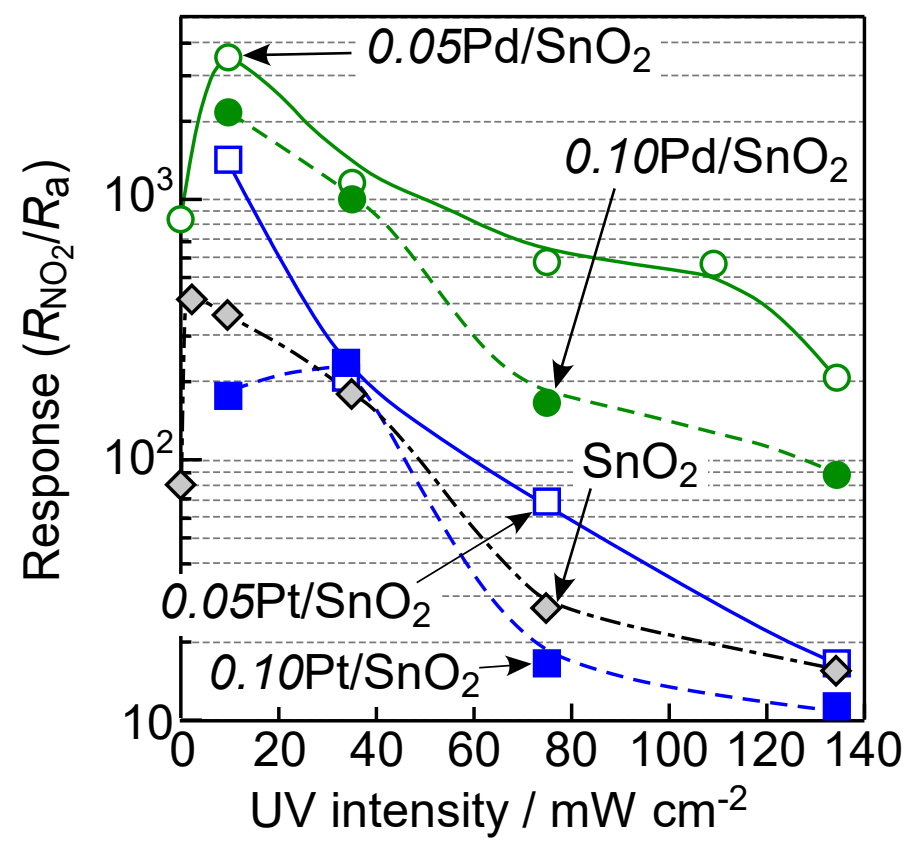

Fig. 10. Hyodo et al. 


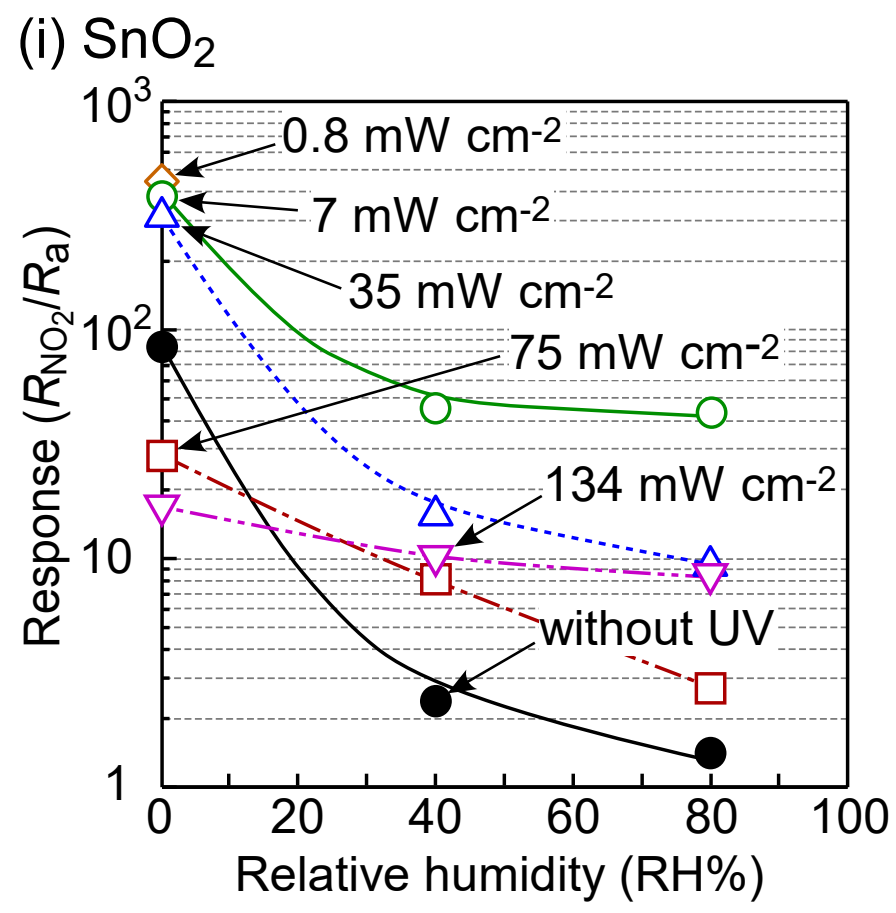

(ii) $0.05 \mathrm{Pd} / \mathrm{SnO}_{2}$

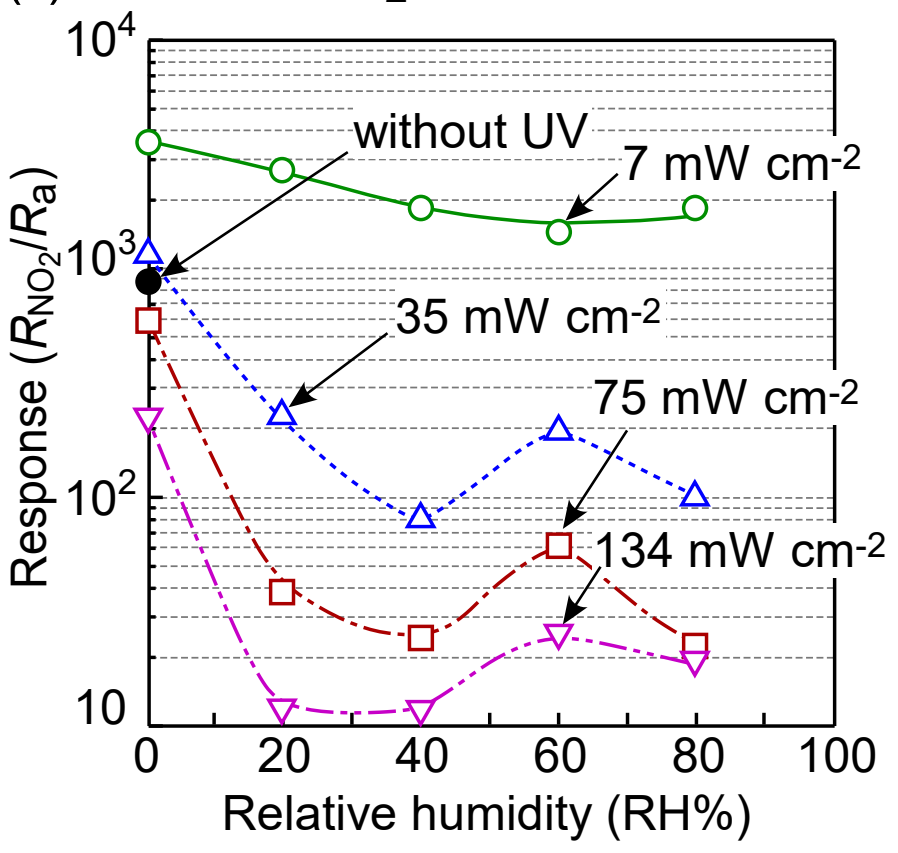

Fig. 11. Hyodo et al. 


\section{Supporting Information}

\section{Semiconductor-type $\mathrm{SnO}_{2}$-based $\mathrm{NO}_{2}$ sensors operated at room temperature under UV-light irradiation}

Takeo Hyodo*, Kaoru Urata, Kai Kamada, Taro Ueda, and Yasuhiro Shimizu

Graduate School of Engineering, Nagasaki University

1-14 Bunkyo-machi, Nagasaki 852-8521, Japan

*Corresponding author: hyodo@nagasaki-u.ac.jp 

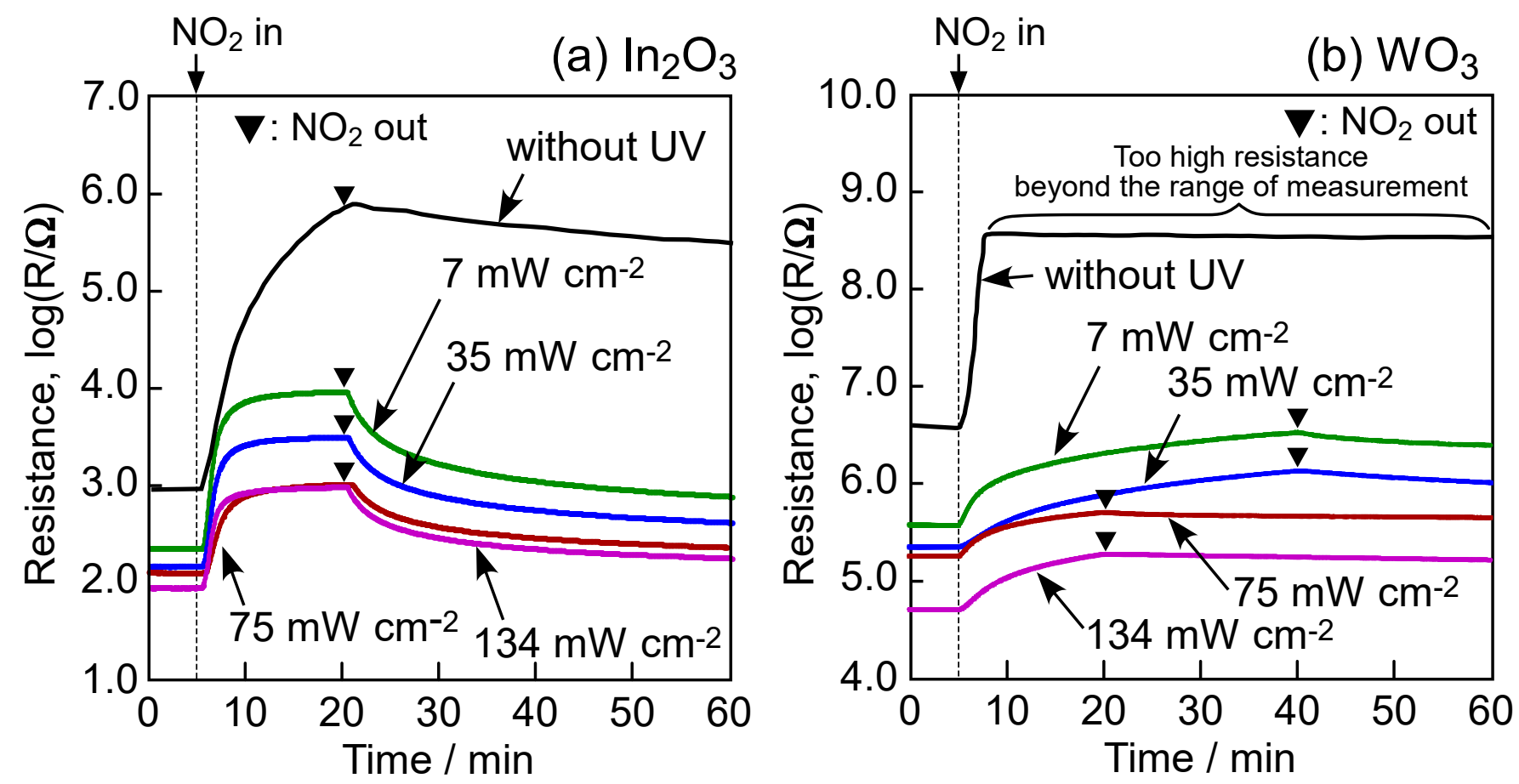

Fig. S1. Response transients of $\ln _{2} \mathrm{O}_{3}$ and $\mathrm{WO}_{3}$ sensors to $5 \mathrm{ppm} \mathrm{NO} \mathrm{N}_{2}$ at $30^{\circ} \mathrm{C}$ in dry air under different UV-light irradiation intensities. 
(a) $T_{\mathrm{RS}}(90)$

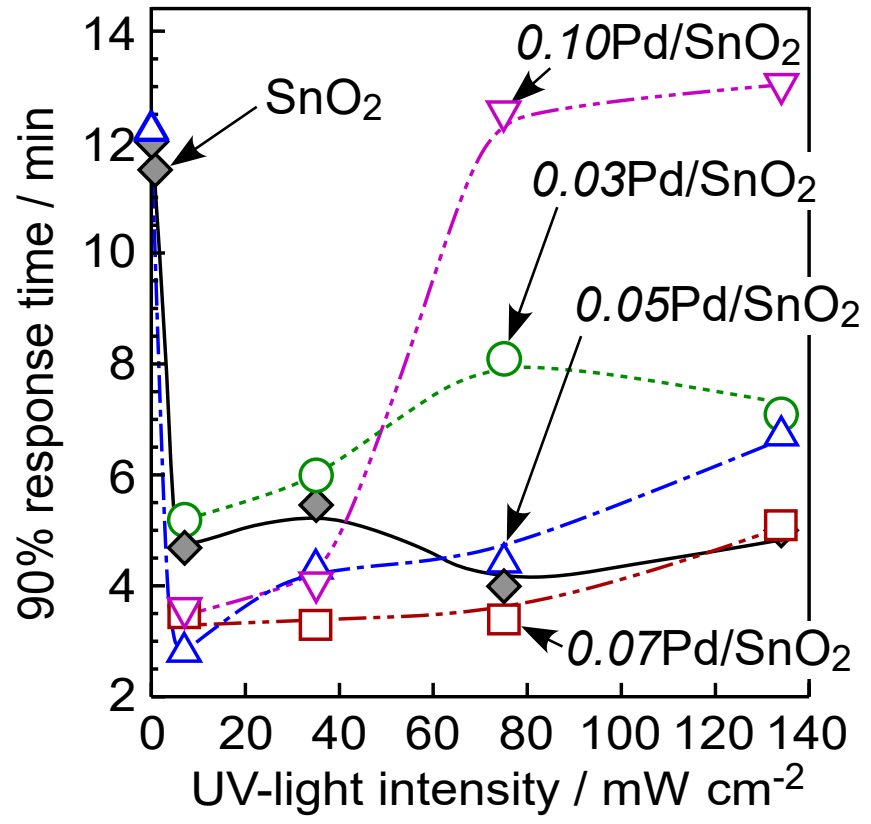

(b) $T_{\mathrm{RC}}(60)$

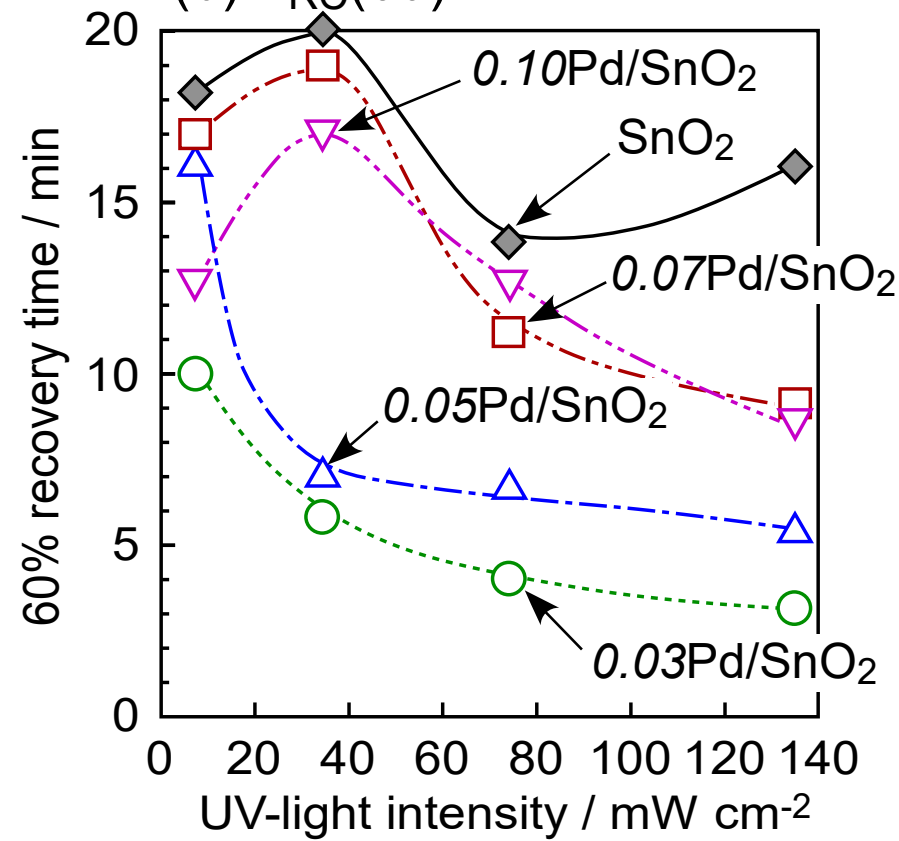

Fig. S2. Variations in $90 \%$ response and $60 \%$ recovery times ( $T_{\mathrm{RS}}(90)$ and $T_{\mathrm{RC}}(60)$, respectively) of all $n \mathrm{Pd} / \mathrm{SnO}_{2}$ sensors with UV-light intensity, together with those of $\mathrm{SnO}_{2}$ sensor. 
(a) $0.05 \mathrm{Pd} / \mathrm{In}_{2} \mathrm{O}_{3}$

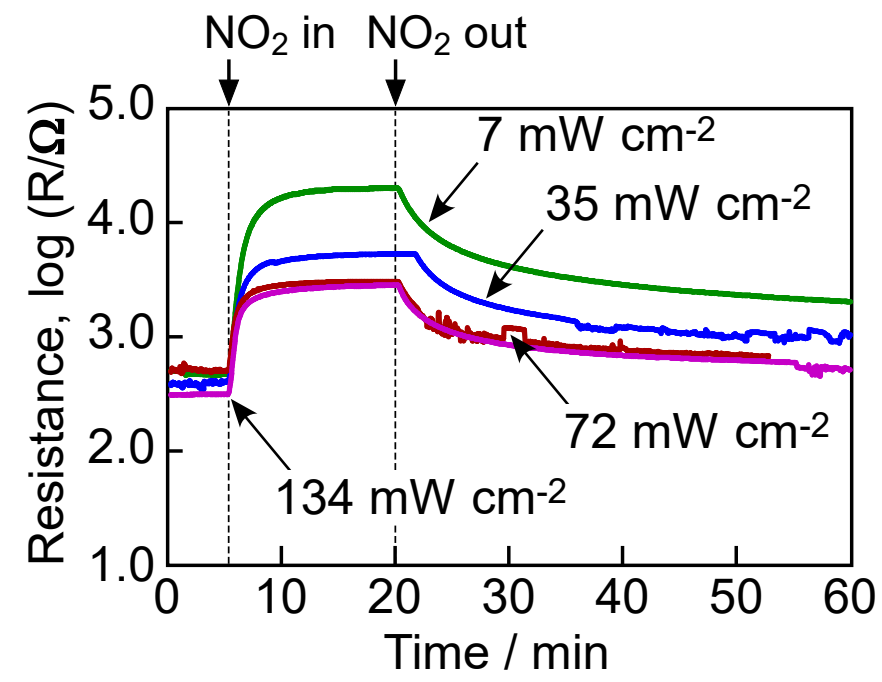

(b) $0.07 \mathrm{Pd} / \mathrm{In}_{2} \mathrm{O}_{3}$

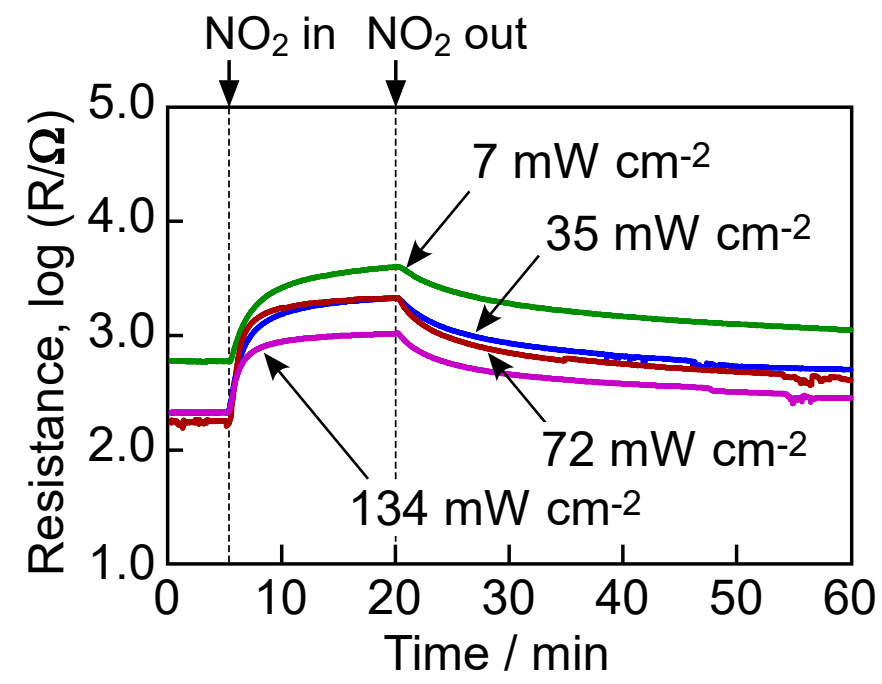

Fig. S3. Response transients of $0.05 \mathrm{Pd} / \mathrm{In}_{2} \mathrm{O}_{3}$ and $0.07 \mathrm{Pd} / \mathrm{In}_{2} \mathrm{O}_{3}$ sensors to $5 \mathrm{ppm} \mathrm{NO}$ at $30^{\circ} \mathrm{C}$ in dry air under different UV-light irradiation intensities. 


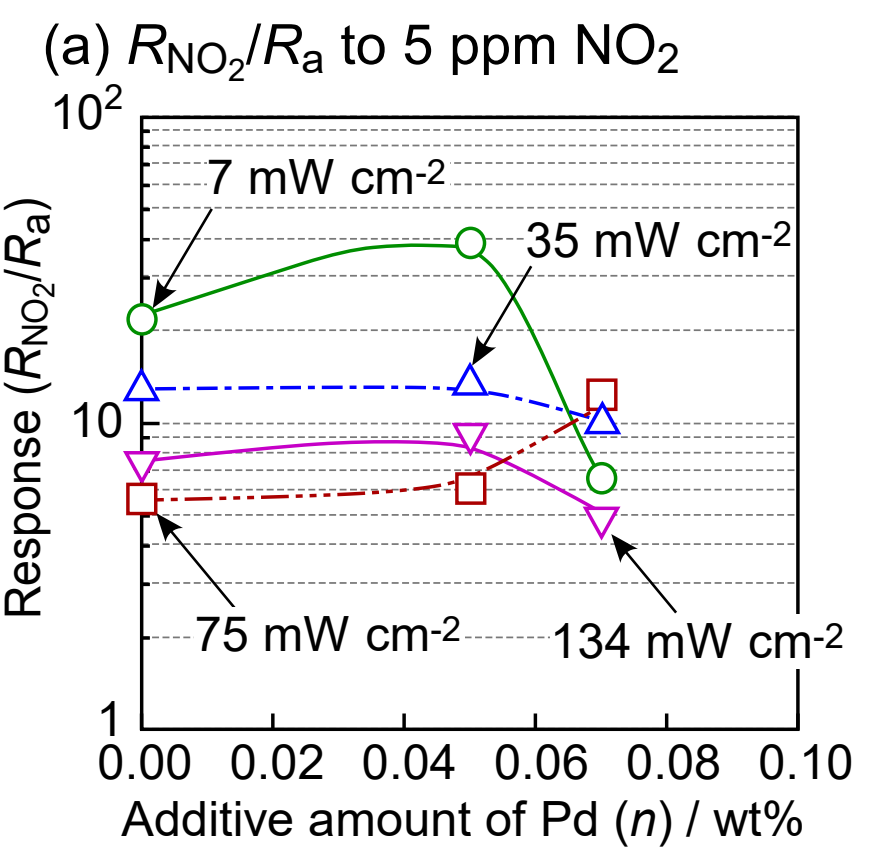

(b) Resistance in dry air

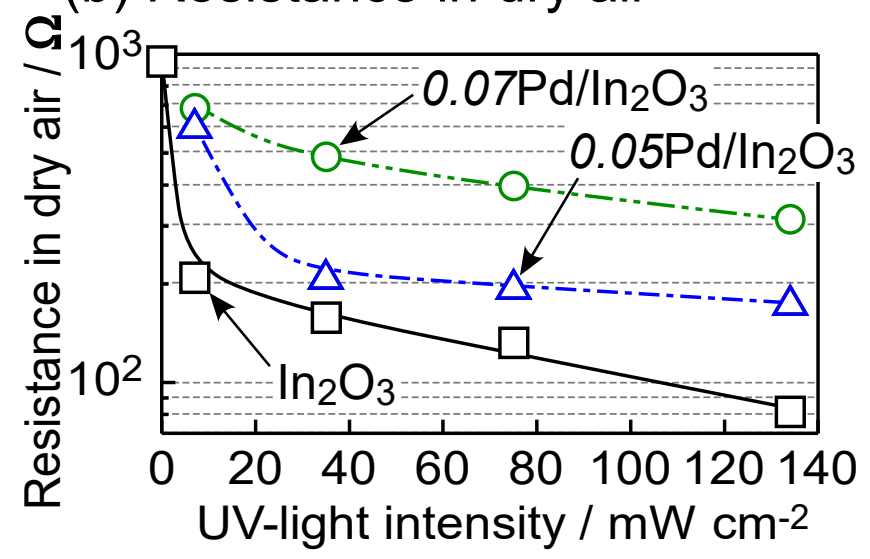

Fig. S4. Variations in response of $0.05 \mathrm{Pd} / \mathrm{In}_{2} \mathrm{O}_{3}$ and $0.07 \mathrm{Pd} / \mathrm{In}_{2} \mathrm{O}_{3}$ sensors to $5 \mathrm{ppm} \mathrm{NO} \mathrm{NO}_{2}\left(R_{\mathrm{NO}_{2} /} / R_{\mathrm{a}}\right)$ and resistance in dry air $\left(R_{\mathrm{a}}\right)$ with the amount of Pd loaded and UV-light intensity, respectively, together with those of $\ln _{2} \mathrm{O}_{3}$ sensor. 


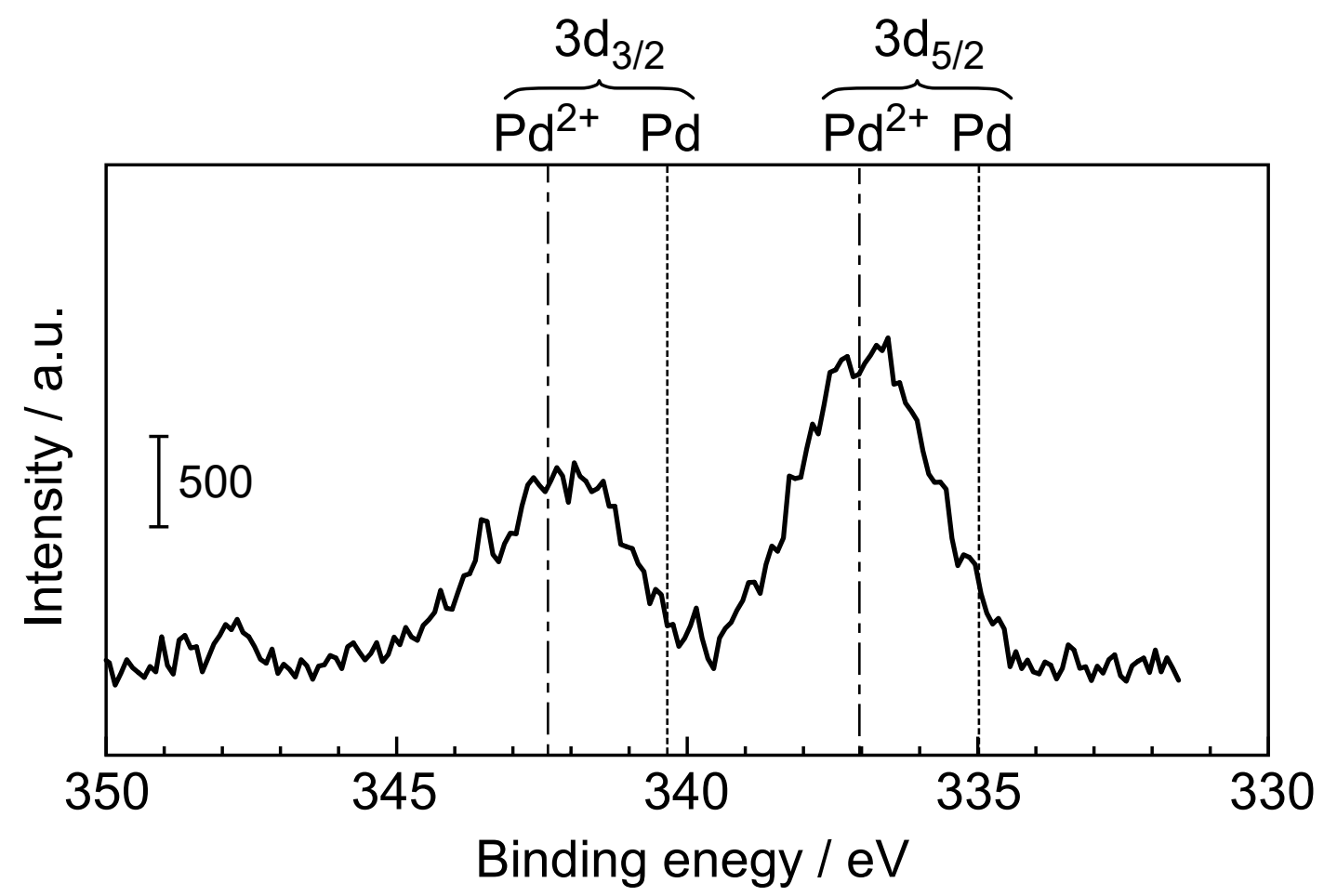

Fig. S5. XPS spectrum of $\mathrm{Pd}$ on the surface of $0.07 \mathrm{Pd} / \mathrm{In}_{2} \mathrm{O}_{3}$ powder after heat treatment at $500^{\circ} \mathrm{C}$ for $1 \mathrm{~h}$ in ambient air. 
(a) $0.05 \mathrm{Pt} / \mathrm{SnO}_{2}$

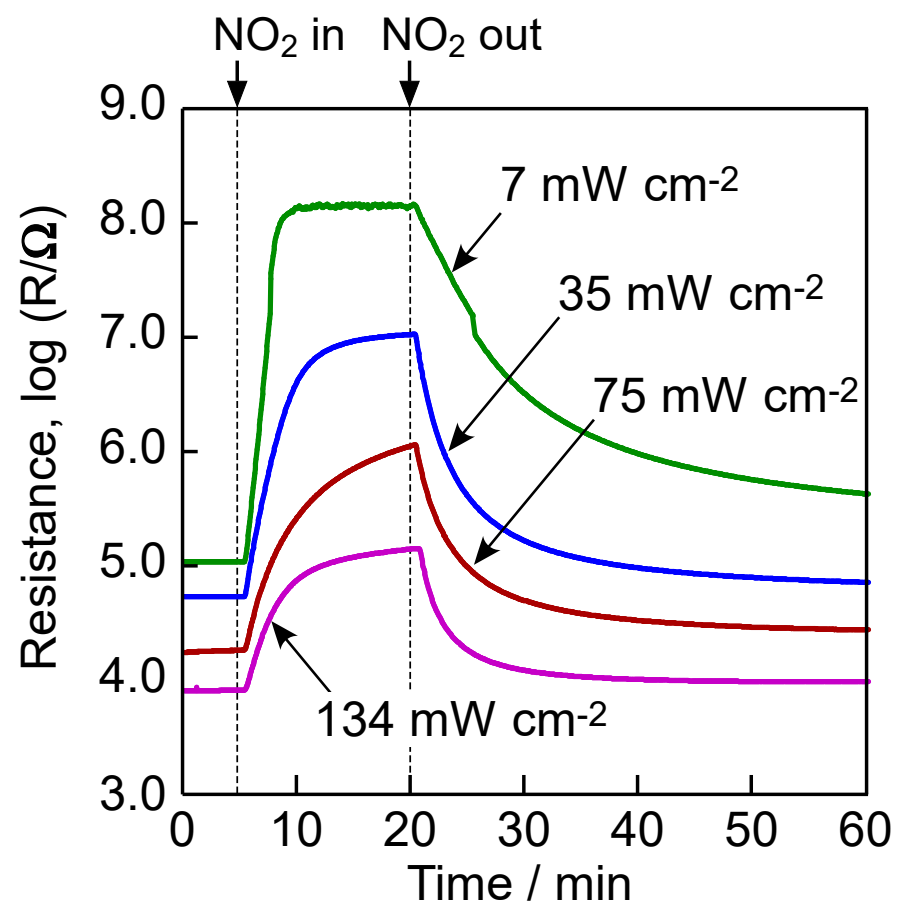

(b) $0.10 \mathrm{Pt} / \mathrm{SnO}_{2}$

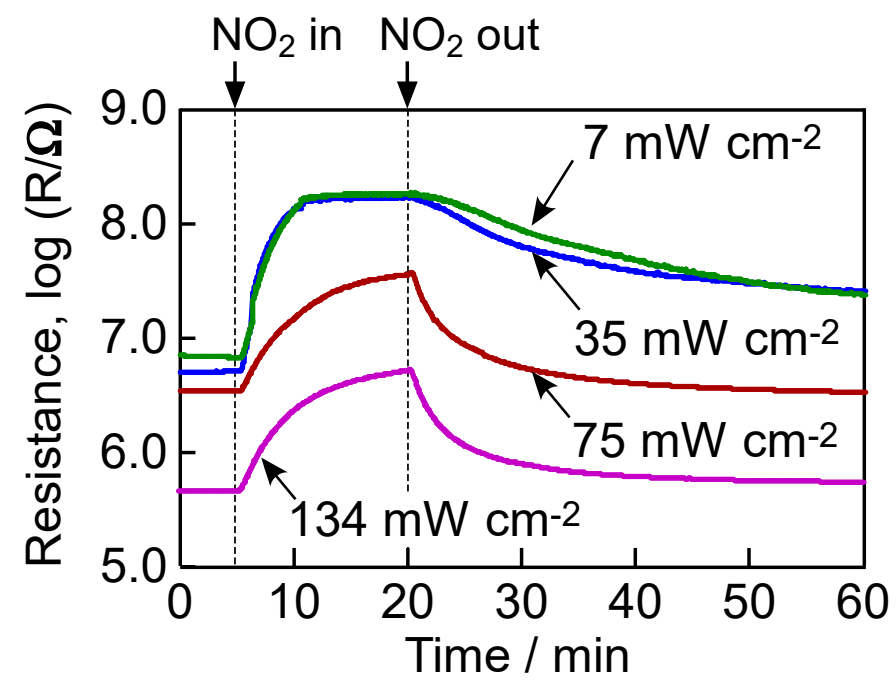

Fig. S6. Response transients of $0.05 \mathrm{Pt} / \mathrm{SnO}_{2}$ and $0.10 \mathrm{Pt} / \mathrm{SnO}_{2}$

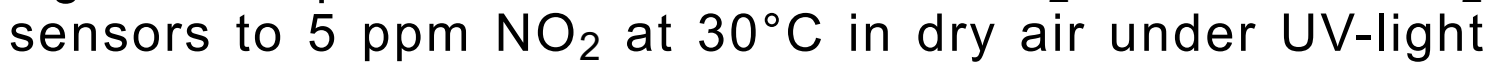
irradiation. 
(a) $\mathrm{SnO}_{2}$

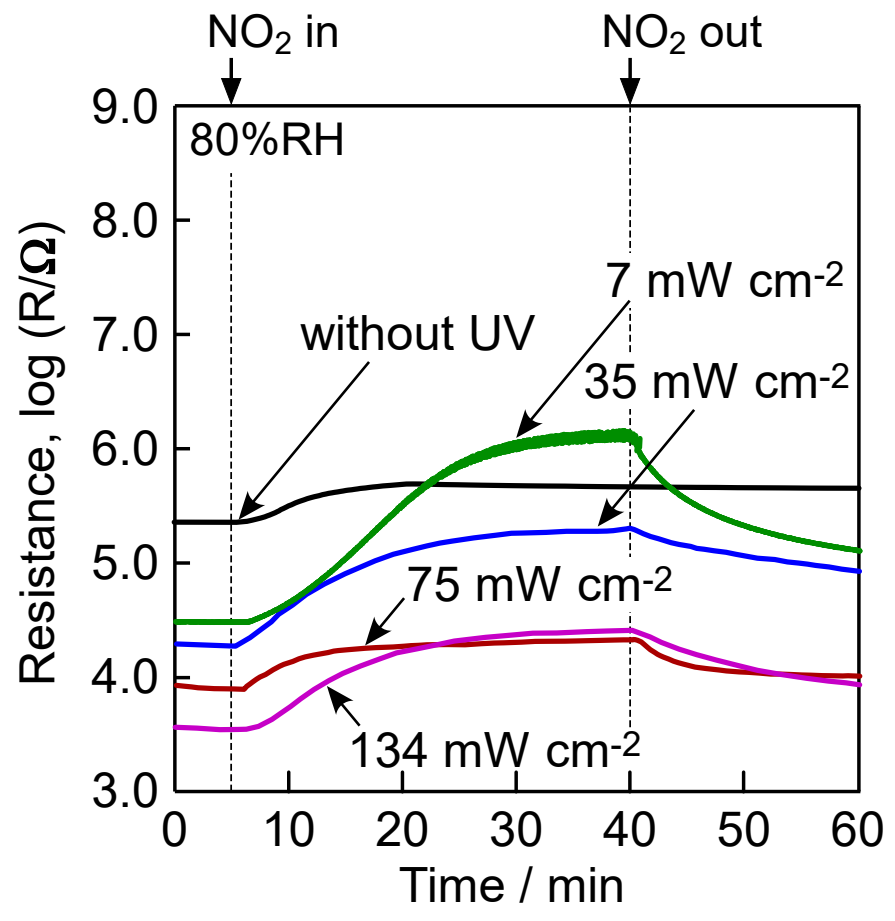

(b) $0.05 \mathrm{Pd} / \mathrm{SnO}_{2}$

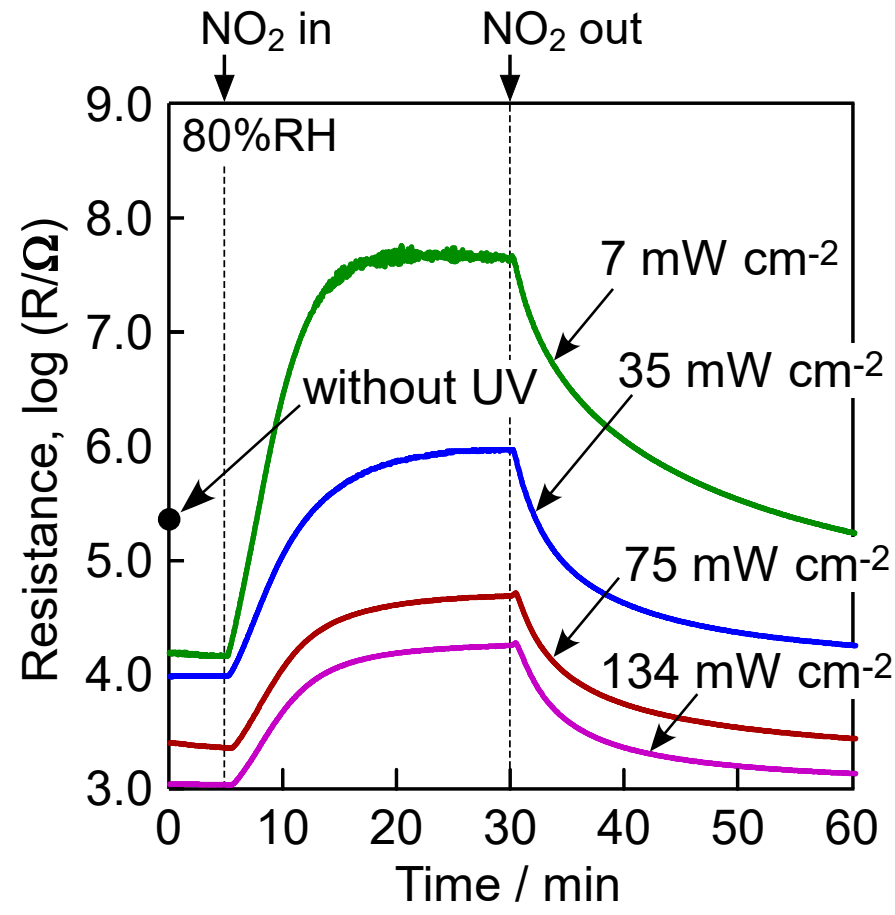

Fig. S7. Response transients of $\mathrm{SnO}_{2}$ and $0.05 \mathrm{Pd} / \mathrm{SnO}_{2}$ sensors to $5 \mathrm{ppm} \mathrm{NO}$ at $30^{\circ} \mathrm{C}$ in wet air $(80 \% \mathrm{RH})$ under different UV-light irradiation intensities. 